\title{
Downscaling over Vietnam using the stretched-grid CCAM: verification of the mean and interannual variability of rainfall
}

\author{
Kim C. Nguyen $\cdot$ Jack J. Katzfey $\cdot$ John L. McGregor
}

Received: 9 April 2013/Accepted: 12 October 2013/Published online: 26 October 2013

(C) The Author(s) 2013. This article is published with open access at Springerlink.com

\begin{abstract}
Rainfall over Vietnam is highly variable from north to south, due to the interaction of the monsoonal winds with the terrain. There is high rainfall from April to September, and little rainfall from October to March (except along the central Vietnam coast). In order to study the ability of the Commonwealth Scientific and Industrial Research Organisation stretched-grid Conformal Cubic Atmospheric Model (CCAM) to capture the climatic and interannual variability of rainfall, downscaled simulations at approximately $20 \mathrm{~km}$ horizontal resolution over the region were produced for the period 1979-2001. A scaleselective digital filter was used to force the winds, temperature and sea-level pressure from the ERA-Interim reanalysis for length scales greater than about $700 \mathrm{~km}$. For wind and temperature, the forcing is applied for pressuresigma levels above about 0.9. ERA-Interim sea surface temperatures were used over the oceans. The simulations were primarily validated against the gridded Asian Precipitation Highly Resolved Observational Data Integration Toward Evaluation of the Water Resources rainfall dataset and station observations using standard statistical methods. It was found that CCAM reproduces well the amount and spatial variability of rainfall, with an area-averaged bias for the entire study domain of less than $1 \mathrm{~mm} \mathrm{day}^{-1}$; CCAM is also able to capture the rainfall pattern under different $\mathrm{El}$ Niño Southern Oscillation phases reasonably well for the dry season. For interannual variability, the simulation generally performed better for North and Central Vietnam
\end{abstract}

K. C. Nguyen $(\bowtie) \cdot$ J. J. Katzfey · J. L. McGregor Centre for Australian Weather and Climate Research (A partnership between CSIRO and the Bureau of Meteorology), PB1, Aspendale, VIC 3195, Australia

e-mail: kim.c.nguyen@csiro.au than for South Vietnam, where rainfall variability was overestimated.

Keywords Regional climate model · Downscaling · CCAM $\cdot$ Validation $\cdot$ Vietnam

\section{Introduction}

Vietnam stretches along the South China Sea (SCS), also known as East Vietnam Sea (EVS), from 9 to $23^{\circ} \mathrm{N}$ with a narrow coastline and mountain range in the middle (Fig. 1a). Most socio-economic activities are concentrated on the Red River and Mekong River deltas. Income heavily depends on agriculture (GDP, $13.85 \%$ in 2009) and tourism (www.gso.gov.vn/default_en.aspx?tabid=508\&idmid= $\&$ ItemID=13276).

Vietnam is a tropical country and experiences two types of monsoon: a southwest summer monsoon (hereafter wet season) from April to September and a northeast monsoon or winter monsoon (hereafter dry season) from October to March. This terminology is a simplified description of the wet and dry seasons. As explained by Phan et al. (2009), the "wet seasons" are (May-October, August-December, May-October) respectively for (North, Central, South) Vietnam, whilst the dry seasons are respectively (November-March, January-July, November-March). As elaborated by Phan et al. (2009), in North Vietnam the maximum rainfall occurs in July-August and is related to the activities of the ITCZ and tropical cyclones; in South Vietnam and the Central Highlands it occurs in August-October and is related to the warm-moist maritime airflow originating from the Bay of Bengal; in Central Vietnam (mostly located in the east side of Truong Son Range) the maximum rainfall occurs in September-November and is 
Fig. 1 a CCAM orography (elevation in $\mathrm{m}$ ) with the high resolution region enclosed by a rectangle. Red text denotes North and South Vietnam, the Truong Son Range (Central Vietnam). b Observed stations (red dots) are provided by HUS and IMHEN; pink squares show Bacquang (North Vietnam), Aluoi, Namdong, Tramy and Bato (Central Vietnam), Nhatrang, Pharang, Phuquy and Truongsa (South Vietnam) stations. c CCAM $20 \mathrm{~km}$ horizontal resolution land-sea mask, where stations on land are shown by red dots and island stations are shown by blue dots. Note that all island stations and two coastal stations Vungtau (blue square) and Quynhon (blue square) are sea points in the model (a)

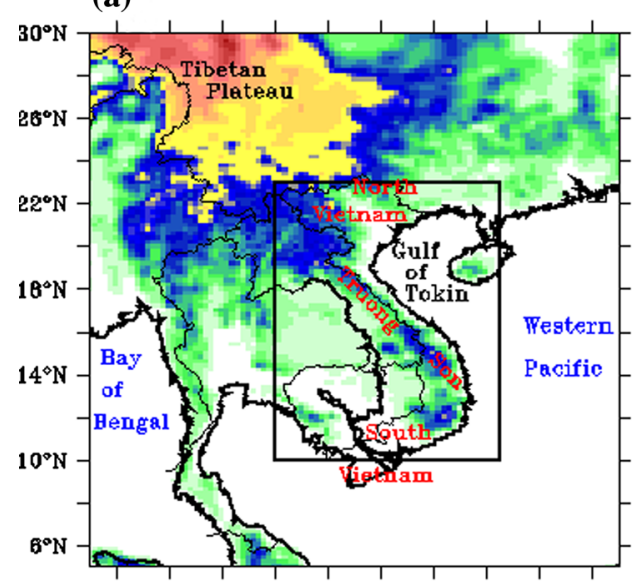

(c) CCAM 20 KM LAND-SEA MASK

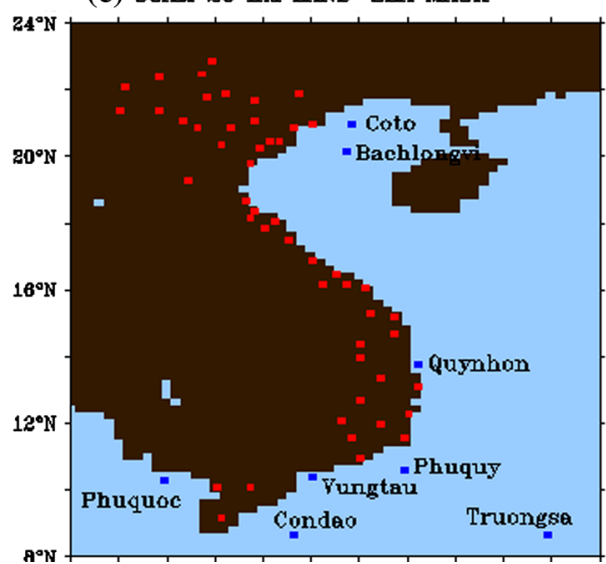

(b)

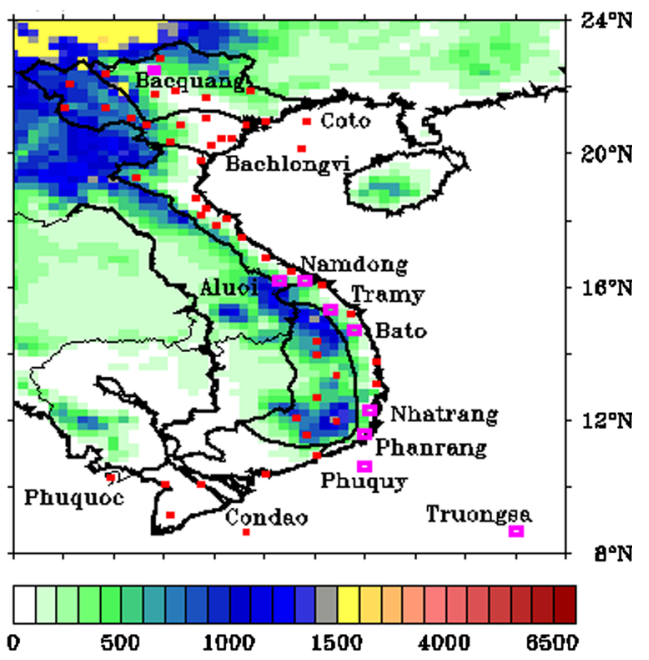

mainly caused by interactions between the cold-air penetrating from the north, activities of the ITCZ, tropical cyclones, and orography.

Wang and Chang (2012) conducted a numerical simulation to investigate the relationship between the largescale monsoon circulation and precipitation, with and without orography, over the Indochina Peninsula (including Vietnam). The study found that the monsoon rainfall over this region is highly localised, being strongly influenced by interaction between local wind and orography. Furthermore, Central Vietnam experiences landfall from typhoons originating from the western North Pacific during the winter monsoon, which causes flood, loss of life and infrastructure damage. In 1997, typhoon Linda was the deadliest typhoon of the century, causing the loss of thousands of lives, and the destruction of over 150,000 houses. The southern tip of Vietnam, which was on the storm track, suffered the largest damage. More recently, typhoon Kai-Tak (19-20 August 2012) made landfall and killed about 20 people, with more than 12,000 houses damaged, more than 30,000 ha of cropland flooded, about 200 trees uprooted and a huge sink-hole in the middle of the road according to the United Nations (http://reliefweb. int/report/viet-nam/typhoon-kills-17-vietnam). Rainfall and typhoon activity are strongly correlated with the El Niño Southern Oscillation (ENSO) in the winter monsoon season, particularly in Central Vietnam (Yen et al. 2011; Phan 2002).

Recently, the effects of climate change are apparent in Vietnam. For example, salt-water intrusion in South Vietnam has forced some farmers to give up their rice farming and adopt fish and shrimp farming. The Asian summer monsoon seasons, including those of Vietnam, are also observed to arrive earlier (Kajikawa et al. 2012). The rainfall in May is showing increases whereas the rainfall in June shows decreases (Kajikawa et al. 2012). This is of great concern for Vietnam due to the consequent need for new infrastructure and new skills.

In this study, we focus our investigation on the capabilities of Conformal Cubic Atmospheric Model (CCAM) simulation of mean climate, forced by initial and broadscale conditions provided by ERA-Interim (Simmons et al. 2006) for the period 1979-2001. The study provides a measure of the skill of CCAM's convective parameterization and the capability of CCAM to capture the orographic influences on the creation of rainfall for the 
region. Descriptions of the data used, the model and CCAM grid setup are provided in Sect. 2. Results of the simulations are discussed in Sect. 3 for present-day conditions (1979-2001). Conclusions are given in Sect. 4.

\section{Data used and model setup}

Due to some differences found in "observed" data sets (Krajewski et al. 2000; Nguyen et al. 2011), in particular over Asia (Yatagai et al. 2005, 2012), we used four different gridded observed data sets to validate the model results. The observed data sets are the CPC Merged Analysis of Precipitation (CMAP, Xie and Arkin 1997), the Global Precipitation Climatology Project data set (GPCP, Adler et al. 2003), University of East Anglia Climatic Research Unit (CRU, New et al. 1999) and Asian Precipitation Highly Resolved Observational Data Integration Toward Evaluation of the Water Resources (APHRODITE), where CMAP and GPCP have resolution $2.5^{\circ}$, CRU $0.5^{\circ}$ and APHRODITE $0.25^{\circ}$. APHRODITE has high resolution but the number of station data included in this data set over Vietnam is sparse (Fig. 1b). Also APHRODITE and CRU have values only over land. More details on the APHRODITE data set can be found in Yatagai et al. (2012). Significant differences between the two meanrainfall data sets are investigated by the Student $t$ test.

The verification is focused on rainfall for two seasons, wet (from April to September) and dry (from October to March). The model results are also compared to station observations provided by Vietnamese scientists from Hanoi University of Science (HUS) and the Vietnam Institute of Meteorology, Hydrology and Environment (IMHEN). Statistical methods used are mean, bias (model minus observation), root mean square error (RMSE). Since the model was forced every $6 \mathrm{~h}$ by ERA Interim, we also explore model performance using forecast skill scores (www.cawcr.gov.au/projects/verification/\#Standard_verifi cation_methods) such as accuracy, bias score, probability of detection, false alarm rates, success ratio, critical success index and equitable threat score. Formulations of the above statistical variables are given in the "Appendix".

For the past decade the CCAM has been the mainstay of Commonwealth Scientific and Industrial Research Organisation (CSIRO) dynamical downscaling (McGregor 1996, 2005a, b; McGregor and Dix 2001, 2008). CCAM is an atmospheric Global Climate Model (GCM) formulated on the conformal-cubic grid. CCAM includes a fairly comprehensive set of physical parameterizations. The GFDL parameterizations for long-wave and short-wave radiation (Schwarzkopf and Fels 1991; Lacis and Hansen 1974) are employed, with interactive cloud distributions determined by the liquid and ice-water scheme of Rotstayn
(1997). The model employs a stability-dependent boundary layer scheme based on Monin-Obukhov similarity theory (McGregor et al. 1993), together with the non-local treatment of Holtslag and Boville (1993). A canopy scheme is included, as described by Kowalczyk et al. (1994), having six layers for soil temperatures, six layers for soil moisture (solving Richard's equation) and three layers for snow. The cumulus convection scheme uses a mass-flux closure, as described by McGregor (2003), and includes downdrafts, entrainment and detrainment. CCAM is not only used for climate studies (Nguyen et al. 2011), it is also used in a short-range weather forecast system (Landman et al. 2012).

In the simulation analysed here, CCAM was run with a variable-resolution grid, having about $20 \mathrm{~km}$ resolution over Vietnam, becoming gradually coarser further away. The large-scale winds, temperatures and mean sea level pressure were forced by the 6-hourly ERA-Interim reanalysis using a scale-selective digital filter (Thatcher and McGregor 2009) forcing at length scales of about $700 \mathrm{~km}$ and larger, which allows finer spatial scales to evolve quite freely. For winds and temperatures the filter is only applied above pressure-sigma level 0.9 in a terrain following coordinate, leaving the boundary layer essentially unperturbed. ERA-Interim sea surface temperatures were used over the oceans.

The region studied is shown in Fig. 1a, along with the surface elevation used by CCAM. The rectangle shows the high-resolution panel having $20 \mathrm{~km}$ horizontal resolution. The high-resolution region spreads over Vietnam, Laos, Cambodia and the eastern part of Thailand. Vietnam has a very narrow middle section (hereafter Central Vietnam) with a complex terrain. The central region is dominated by the Truong Son Range with elevation exceeding 1,200 m; it is described as a mesoscale mountain and its role is important in determining rainfall over Central Vietnam (Xie et al. 2006). In South Vietnam, the region of the Mekong River Delta is fairly flat. North Vietnam is flat over its southeast region, but there is high terrain in the northwest corner near the border with Laos. On the eastern side of Vietnam is the SCS/EVS which is vulnerable to tropical cyclones, in particular affecting Central Vietnam. The model results are also compared with observed stations.

The observed station locations in Vietnam are shown in Fig. 1b. It is seen that stations are sparse in South Vietnam (below $13^{\circ} \mathrm{N}$ ), whereas there is a good network of observed stations in Central Vietnam (stations with latitudes between $13^{\circ} \mathrm{N}$ and $19^{\circ} \mathrm{N}$ ) and in North Vietnam (stations with latitudes above $19^{\circ} \mathrm{N}$ ). The station data are extracted from CCAM and APHRODITE from the nearest grid points. From the model land-sea mask (Fig. 1c), it is seen that CCAM $20 \mathrm{~km}$ resolution is still too coarse to resolve some coastal stations such as Vungtau and Quynhon, and island 
Fig. 2 Mean sea level pressure (shaded) and $10 \mathrm{~m}$ wind, with ERA-Interim (left panel) and CCAM (right panel), for the wet season (top April-September) and the dry season (lower October-March); wind vector of $10 \mathrm{~m} \mathrm{~s}^{-1}$ is indicated

\section{MEAN SEA LEVEL PRESSURE AND $10 \mathrm{~m}$ WIND VECTOR}

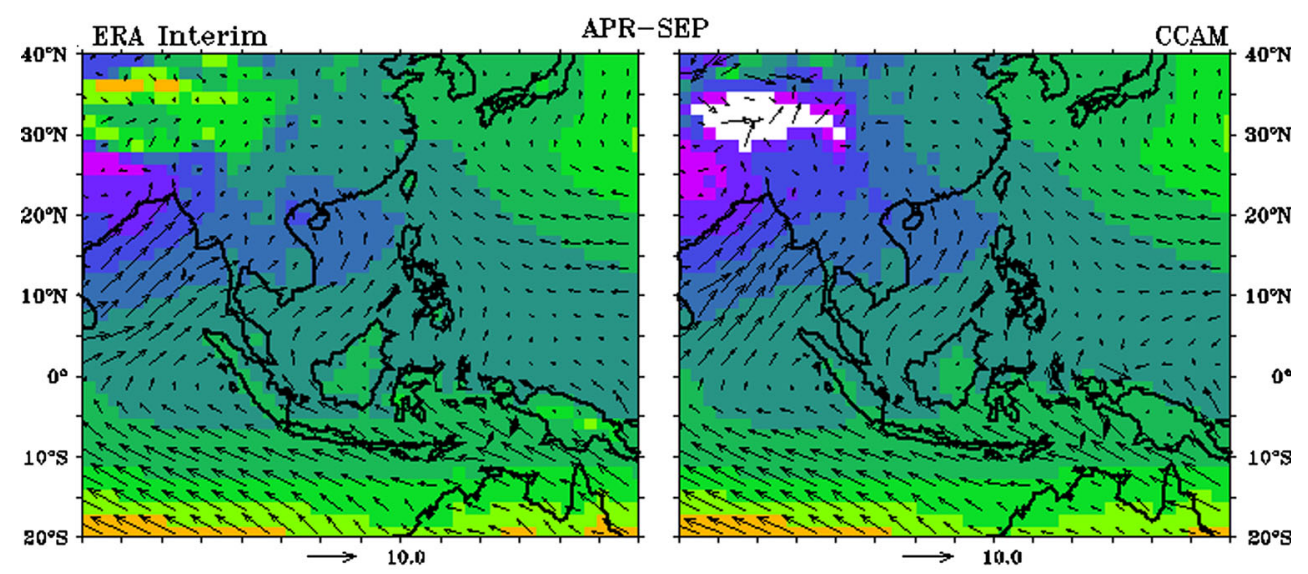

stations such as Phuquoc, Condao, Truongsa and Phuquy in South Vietnam and Coto and Bachlongvi in North Vietnam. These islands are small in size and are not resolved by the $20 \mathrm{~km}$ model horizontal resolution; therefore these islands occur as sea points in the simulation.

\section{Results and discussions}

In this Section we focus on two contrasting seasons: wet, from April to September and dry, October to March for mean climate conditions.

\subsection{Meteorological conditions at the surface}

The CCAM-simulated mean (1979-2001) $10 \mathrm{~m}$ wind compares well with that of ERA-Interim, as shown in Fig. 2 for both seasons. This is partly a result of the largescale spectral nudging which was applied to data above pressure-sigma level 0.9. The mean sea level pressure (MSLP, shaded) matches the ERA-Interim data very well, except over the Himalayas. The apparent differences over the Himalayas are partly related to different methods of reduction to sea level in the analyses and model.

In the wet southwest monsoon season (April-September, upper panels of Fig. 2), the southwesterly wind arrives to the region from the Bay of Bengal where wind is strongest at around $6-10 \mathrm{~m} \mathrm{~s}^{-1}$. Over the northwest Pacific, the wind is weaker and anti-cyclonic around the subtropical high. In the Northern Hemisphere, the low pressure regions are located over the Bay of Bengal and over the SCS/EVS. Meanwhile the high pressure system from the Southern Hemisphere extends northward with its centre over Borneo and directs the warm and moist maritime air into South Vietnam, causing rain to fall in this region.

In the dry season (October to March, lower panels of Fig. 2), the Siberian High is located over the northern boundary and extends over the Sea of Japan and directs cold and dry air into North Vietnam, to the East China Sea and to the SCS/EVS. Air flowing into Central and South Vietnam from the SCS/EVS is warm and moist. Winds over the SCS/EVS and western Pacific are strong, 8-10 $\mathrm{m} \mathrm{s}^{-1}$ during the dry season. 
Fig. $310 \mathrm{~m}$ wind speed biases (shaded), for wet season (left April-September) and dry season (right October-March), only biases at $95 \%$ significance level (by Student $t$ test) are shown

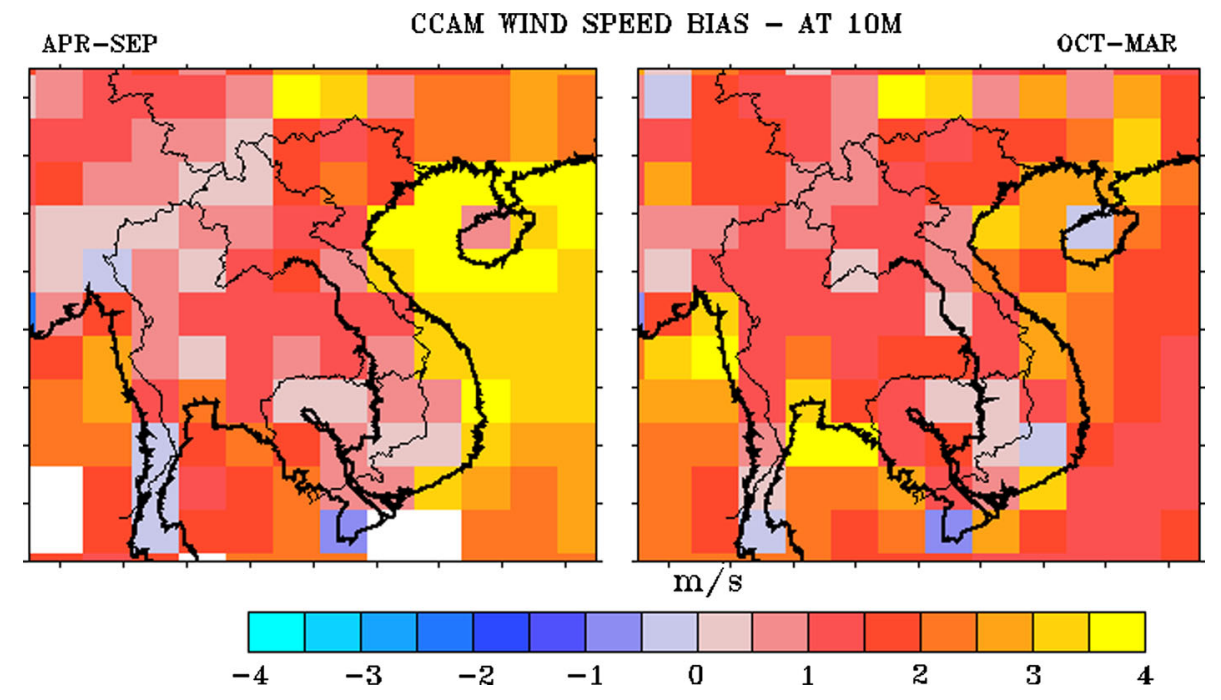

Even though both ERA-Interim and CCAM winds appear similar (Fig. 2), the CCAM $10 \mathrm{~m}$ wind speed is stronger compared to that of ERA-Interim (Fig. 3), except over the southern tip of South Vietnam, where it is slightly weaker. Along the east coast of Vietnam, the bias is large in both seasons. The largest bias is $+4 \mathrm{~m} \mathrm{~s}^{-1}$ along the east coast and SCS/EVS during the wet season; it is slightly less in the dry season.

\subsection{Spatial pattern of mean rainfall}

Verification is now provided for mean rainfall in respect to the wet and dry seasons. The CCAM results are compared with three observed data sets, GPCP, CRU and APHRODITE.

There is a big contrast between the rainfall in the wet and dry seasons. In the wet season (Fig. 4), significant rainfall is evident over the entire domain, with rates of 3-10 mm day ${ }^{-1}$. Regions with highest rainfall are on the windward side of the high terrain, such as along the east coast of the Gulf of Thailand, where the onshore wind interacts with elevation. Laos, located on the west side of the Truong Son Range, receives high rainfall during the southwest monsoon season. High rainfall is also seen over southeast China. On the other hand, Central Vietnam and the northern part of South Vietnam receive less rainfall because these regions are in rain shadows of the mountains to their west. CCAM captures this rainfall pattern, resembling the detailed rainfall pattern of APHRODITE, whereas the GPCP, and to some extent CRU, rainfall patterns are smoother due to their coarser resolutions. GPCP and CRU also produce slightly more rainfall overall when compared with APHRODITE, in particular along the east coast. Also, the wind extends into the SCS/EVS then channels through the Gulf of Tonkin into North Vietnam and forms an anticyclonic circulation centre over the southern part of North
Vietnam (around $18^{\circ} \mathrm{N}$ and $105^{\circ} \mathrm{E}$ ), causing heavy rainfall in this region (Fig. 4). CCAM captures the spatial pattern but it underestimates rainfall amount for the region.

The dry season (Fig. 5) is the northeast monsoon season in Vietnam, when the predominant wind is east to northeasterly from the East China Sea. The interaction of this air with the Truong Son Range produces heavy rainfall on the eastern side of the mountains (Fig. 4). High rainfall $\left(>5 \mathrm{~mm} \mathrm{day}{ }^{-1}\right.$ ) is confined along the narrow east coast of the Truong Son Range, while elsewhere the rainfall rate is about 2-4 mm day ${ }^{-1}$. This pattern is seen in all the observations and in the CCAM simulation. Again, GPCP and CRU rainfall peaks are lower than APHRODITE and are spread over a larger area. CCAM resembles closely the APHRODITE rainfall pattern.

Rainfall biases for the wet and dry seasons are shown in Fig. 6. For simplicity we only show the biases against APHRODITE due to its higher resolution. Only the biases with significance level at the 95th and above are shown. The significance is determined using Student $t$ test based on the 22-year means of APHRODITE and CCAM rainfall. In general, CCAM simulates too much rainfall over Thailand and Cambodia. Over North Vietnam, CCAM underestimates rainfall in the wet season but reproduces well the rainfall amounts in the dry season. Over Central and South Vietnam, CCAM captures well the rainfall amounts in the wet season but slightly overestimates the amounts in the dry season, in particular along the Truong Son Range. Note that this excess rainfall is mainly due to the CCAM heavy coastal rainfall extending slightly further inland than APHRODITE. As shown in Fig. 1 for Vietnam, there are not many observing stations in South and Central Vietnam or in Cambodia (Yatagai et al. 2012), and there are very few stations along the east coast of Vietnam. Therefore biases over these areas may be due to a lack of observations, but also possibly due to some under-representation of 
Fig. 4 Wet season (AprilSeptember) mean rainfall $\left(\mathrm{mm}\right.$ day $^{-1}$ ), with GPCP (top left), CRU (top right), APHRODITE (lower left) and CCAM (lower right)
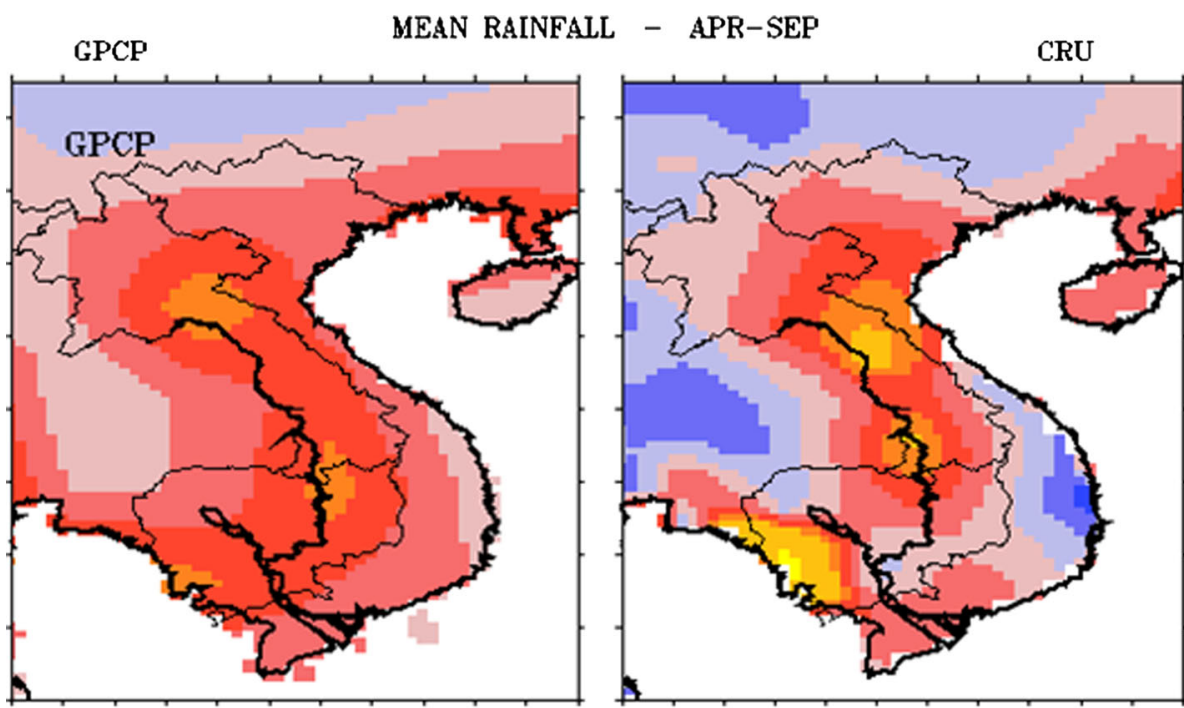

APHRODITE

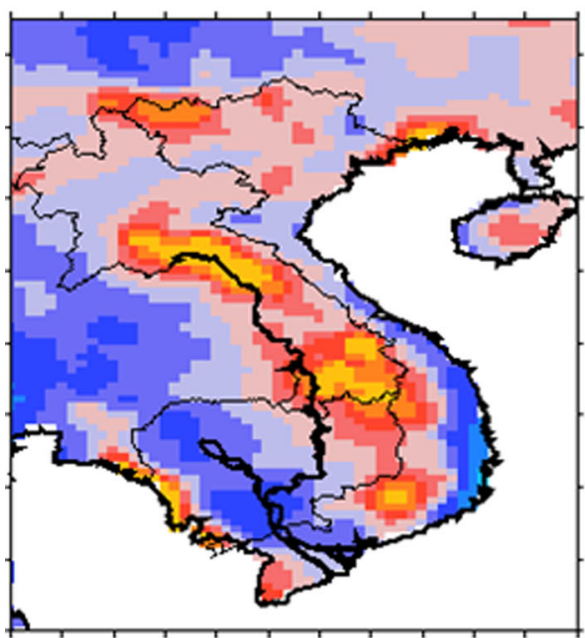

CCAM

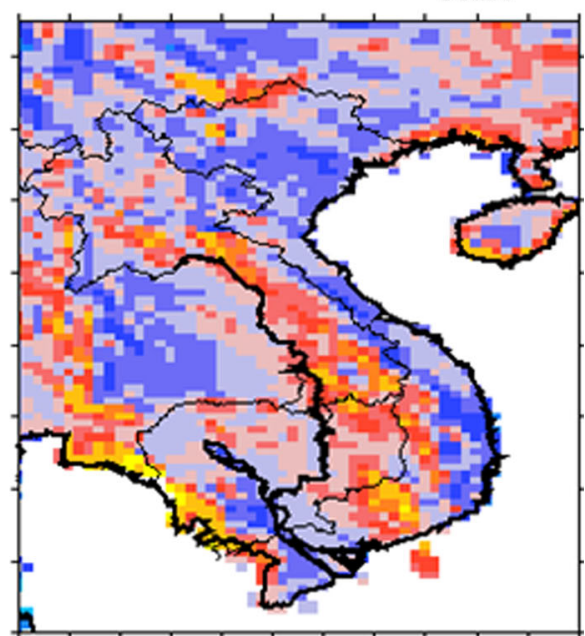

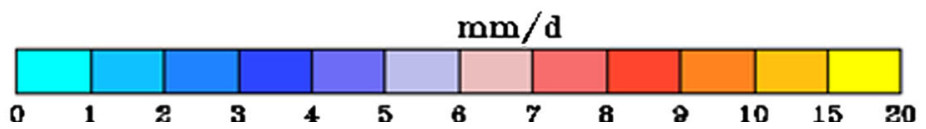

the orography in CCAM. The orography plays an important role in rainfall (e.g. Sarker 1966; Xie et al. 2006; Wang and Chang 2012). As the southwesterly air approaches the mountains, moisture-laden air is forced to rise, producing intense convection on the windward side. The CCAM biases over Thailand, Cambodia and South Vietnam may be due to CCAM having stronger southwesterly monsoon winds over the Bay of Bengal compared to ERA-Interim (Fig. 3, shaded, left panel) as discussed above. However, the biases over Cambodia and South Vietnam are disputable, since GPCP and CRU rainfall are larger than APHRODITE over these regions (Fig. 4). Again, keep in mind that APHRODITE gridded rainfall is interpolated from station observations.

Statistical measurement of the spatial pattern of the mean rainfall over the high-resolution domain enclosed in the black box shown in Fig. 1a is summarized in Table 1, where the statistical formulations are given in the Appendix. CCAM reasonably resembles the APHRODITE and CRU rainfall patterns, in particular in the dry season, which can be seen by the index of agreement (IOA) in Table 1 . IOA can range from 0 (showing disagreement) to 1 (showing agreement) with the observed patterns. The reason for stronger agreement with observed patterns in the dry season is because this season is dominated by high rainfall over the east coast of middle Vietnam (the statistics are dominated by the outliers, Willmott 1982). The CCAM rainfall pattern in the wet season and in the annual mean has lower IOA (close to 0.70). In terms of bias, CCAM slightly underestimates APHRODITE for the dry season and performs well for both the wet season and annual mean. For the mean absolute error (MAE), the error ranges 
Fig. 5 As in Fig. 4 but for the dry season (October-March)

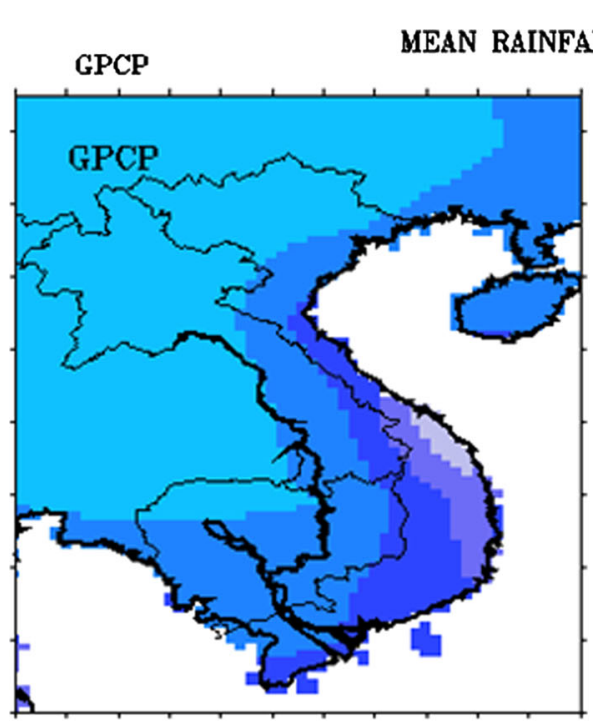

- OCT-MAR

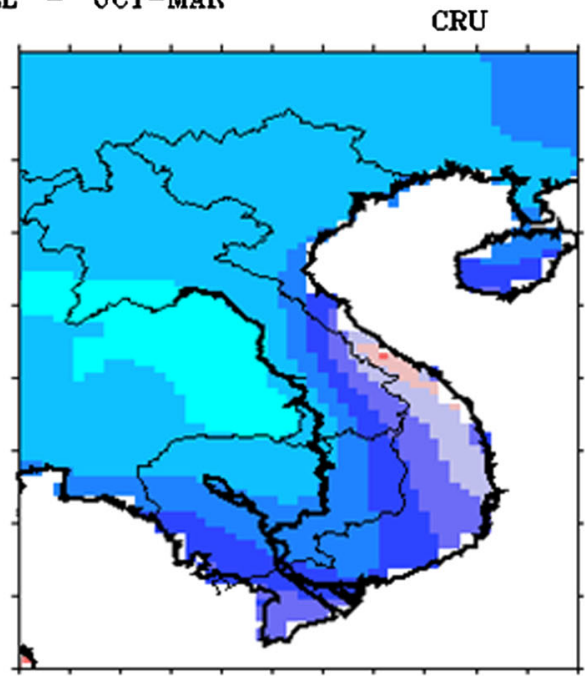

APHRODITE
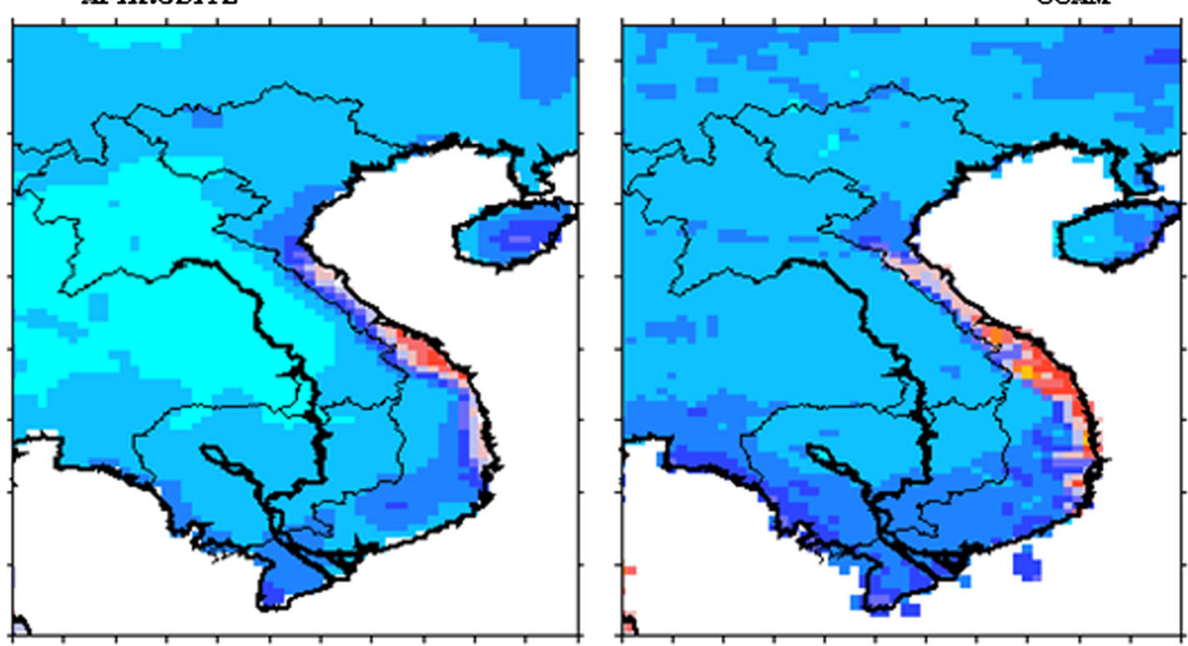

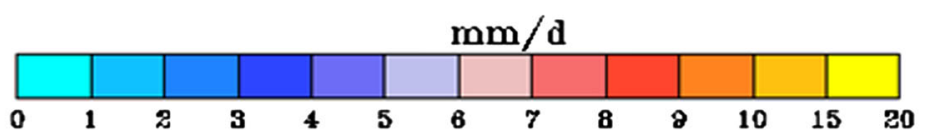

from 0.6 to $1.5 \mathrm{~mm} \mathrm{day}^{-1}$, whereas the root mean square error (RMSE) is between 0.85 and $2.0 \mathrm{~mm} \mathrm{day}^{-1}$. The verification shows similar results for CRU, but the results are slightly worse for CMAP and GPCP likely due to their coarse resolutions.

The 22-year mean monthly rainfall averaged over the high-resolution domain (enclosed by the black box shown in Fig. 1a) is shown in Fig. 7, where the observed rainfall was interpolated onto the CCAM $20 \mathrm{~km}$ grid. The results show that CCAM captures the seasonality well. The amounts of the APHRODITE rainfall are also captured well, except for the period from January to April when CCAM overestimates against all three observed data sets. The percent error is between 20 and $100 \%$ for these months. It is worth mentioning that this is a dry season, so an error of about $10 \mathrm{~mm}$ per month can produce a large percent error. In comparison to CMAP, GPCP and CRU rainfall, CCAM produces insufficient rainfall during MayOctober, 25-50 mm per month less than observations, with largest errors for June to August. However, CCAM overestimates all observations from January to April by similar amounts.

\subsection{Station verification of the mean rainfall}

The verification for the stations located in regions of North, Central and South Vietnam are shown in Figs. 8, 9 and 10, respectively. In North Vietnam (Fig. 8), the wet (upper panel) and dry (lower panel) seasons are apparent with much more rainfall during the wet season. During the wet season, the rainfall at most stations is between 5 and $10 \mathrm{~mm} \mathrm{day}^{-1}$, except for Bacquang station, where the 
Fig. 6 CCAM rainfall bias $\left(\mathrm{mm} \mathrm{day}{ }^{-1}\right)$ against APHRODITE rainfall, where bias is defined as CCAM minus observed rainfall, for the wet/ dry seasons, and only the biases with $95 \%$ significance level and above are plotted

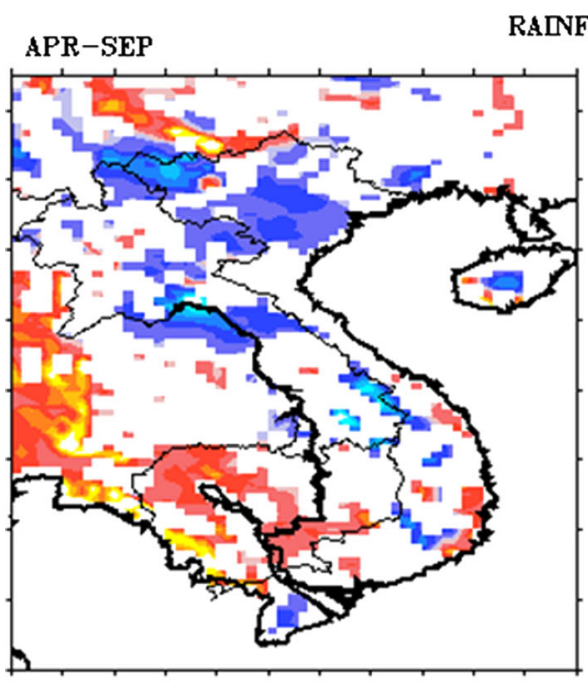

RAINFALL BIAS

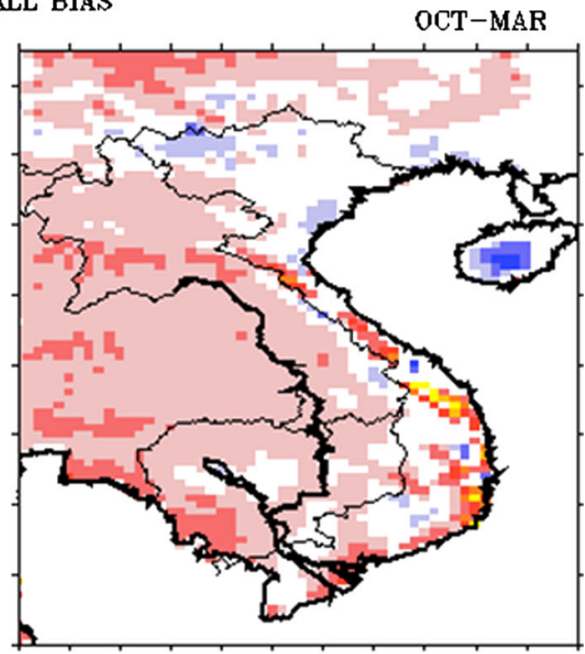

$\mathrm{mm} / \mathrm{d}$

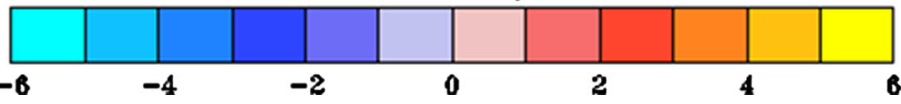

Table 1 Statistical comparisons of mean rainfall pattern against APHRODITE

\begin{tabular}{lcrcc}
\hline & IOA & BIAS & MAE & RMSE \\
\hline Apr-Sep & 0.69 & 0.07 & 1.47 & 2.02 \\
Oct-Mar & 0.87 & -0.44 & 0.60 & 0.85 \\
Annual & 0.67 & -0.16 & 0.87 & 1.18 \\
\hline
\end{tabular}

rainfall is above $20 \mathrm{~mm} \mathrm{day}{ }^{-1}$. This station is located in a valley near the northern border with China (the pink square in Fig. 1b). The nearest stations are Hagiang, with rainfall just above $10.5 \mathrm{~mm}$ day $^{-1}$, Langson and Tuyenquang with rainfall just above $5 \mathrm{~mm}$ day $^{-1}$.

The Bacquang station seems to be an outlier compared to the surrounding stations. The large rainfall amount observed at Bacquang can be explained by the interaction between monsoon circulations and local orography. Bacquang station is located in a "funnel valley" with the "valley mouth" open to the southeast windward direction in both winter and summer monsoons, while the "funnel stem", which is toward to the north-northwest, is intercepted by the high mountains. We believe that the high rainfall over the Bacquang station is probably due to the
Fig. 7 Area-averaged monthlymean rainfall amounts $(\mathrm{mm}$, solid line) for CMAP (black), CRU (blue), GPCP (yellow), APHRODITE (green) and CCAM (red). CCAM absolute (dashed) and percent (bars) biases are shown against each observation, CMAP (black), CRU (blue), GPCP (yellow) and APHRODITE (dark green)

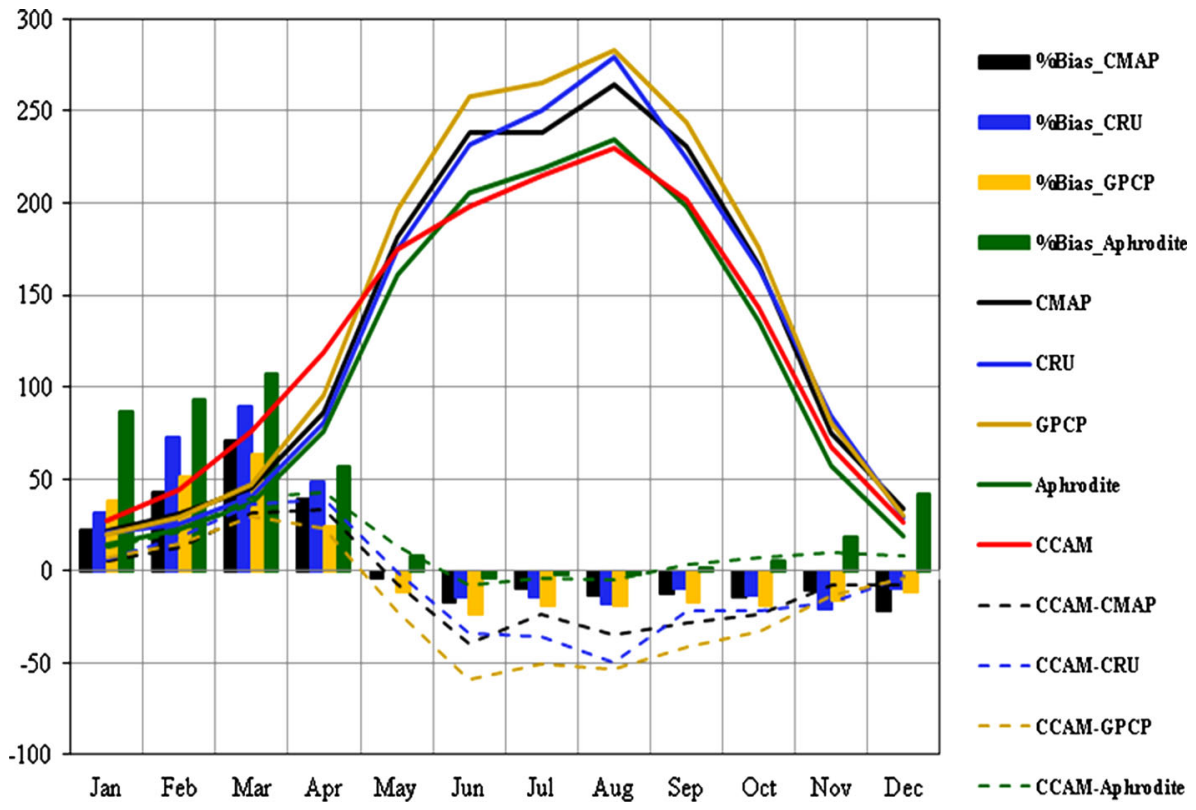


Fig. 8 Wet (upper) and dry (lower) seasonal mean rainfall $\left(\mathrm{mm} \mathrm{day}^{-1}\right)$ at stations located in North Vietnam, all with latitudes above $19^{\circ} \mathrm{N}$, with observed station rainfall in black, CCAM in red, APHRODITE in blue. Bias is defined as the difference between CCAM/APHRODITE and observed rainfall at the station, CCAM in pink and APHRODITE in green. Observed data are provided by the Vietnamese scientists (personal communication)

Fig. 9 As in Fig. 8 but for Central Vietnam stations with latitudes between $13^{\circ} \mathrm{N}$ and $19^{\circ} \mathrm{N}$
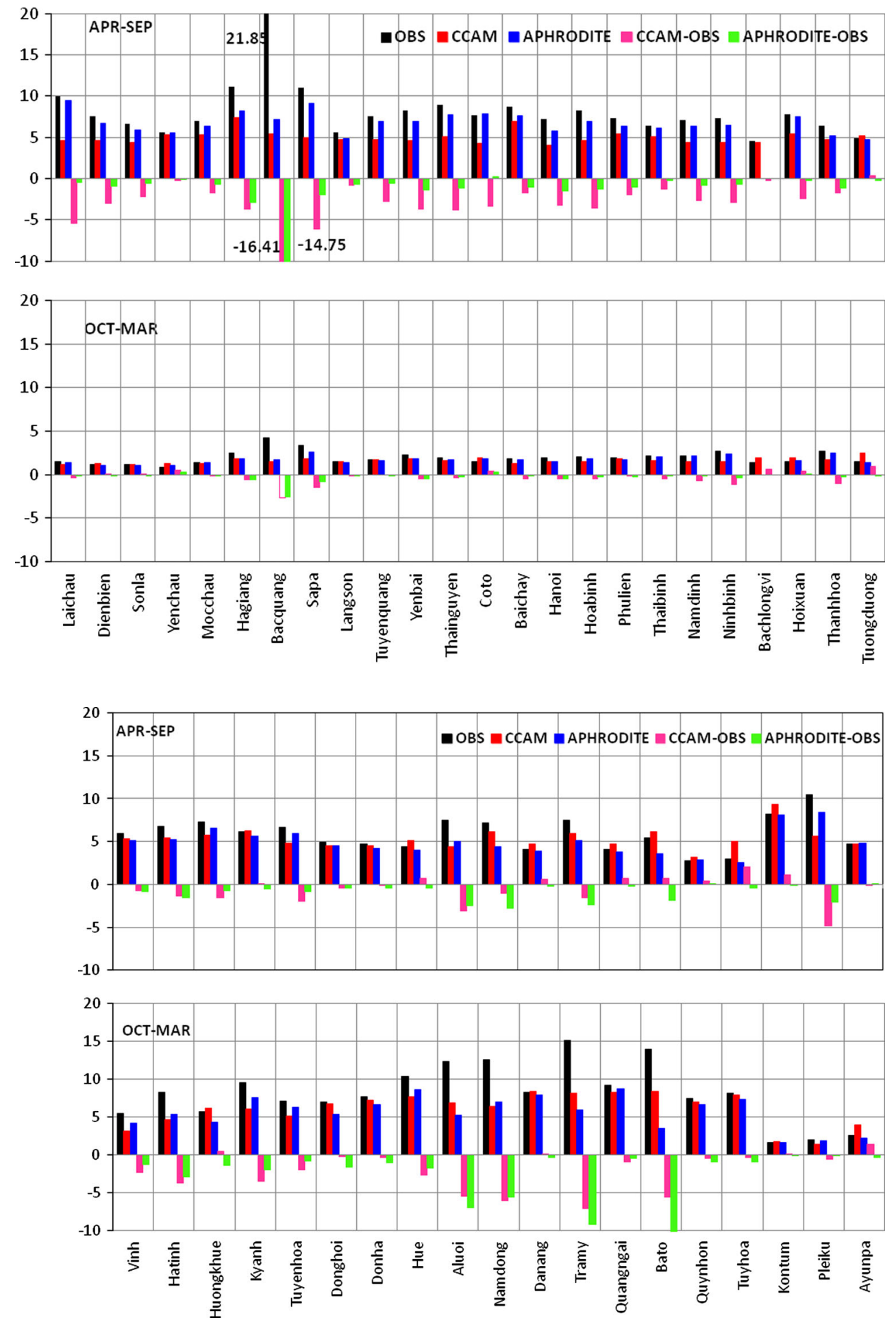

local station orography. Its meteorological elevation is $74 \mathrm{~m}$, whereas in CCAM this station has height $190 \mathrm{~m}$ and is located northeast and upslope of a mountain having height $2,000 \mathrm{~m}$. Therefore in CCAM, it is in a rain shadow in the southwesterly monsoon wet season. Note that CCAM and APHRODITE are in good agreement at this station. In general, CCAM (APHRODITE) underestimates rainfall in North Vietnam with bias within 5 (1) $\mathrm{mm} \mathrm{day}^{-1}$, except Bacquang station. In the dry season (Fig. 8 lower panel) the rainfall is low, less than $5 \mathrm{~mm} \mathrm{day}^{-1}$ at all stations. Both CCAM and APHRODITE agree well with the stations in this season, with small biases.

In Central Vietnam (Fig. 9), the wet and dry season rainfall is not very different. The rainfall rate is 
Fig. 10 As in Fig. 8 but for South Vietnam stations with latitudes south of $13^{\circ} \mathrm{N}$
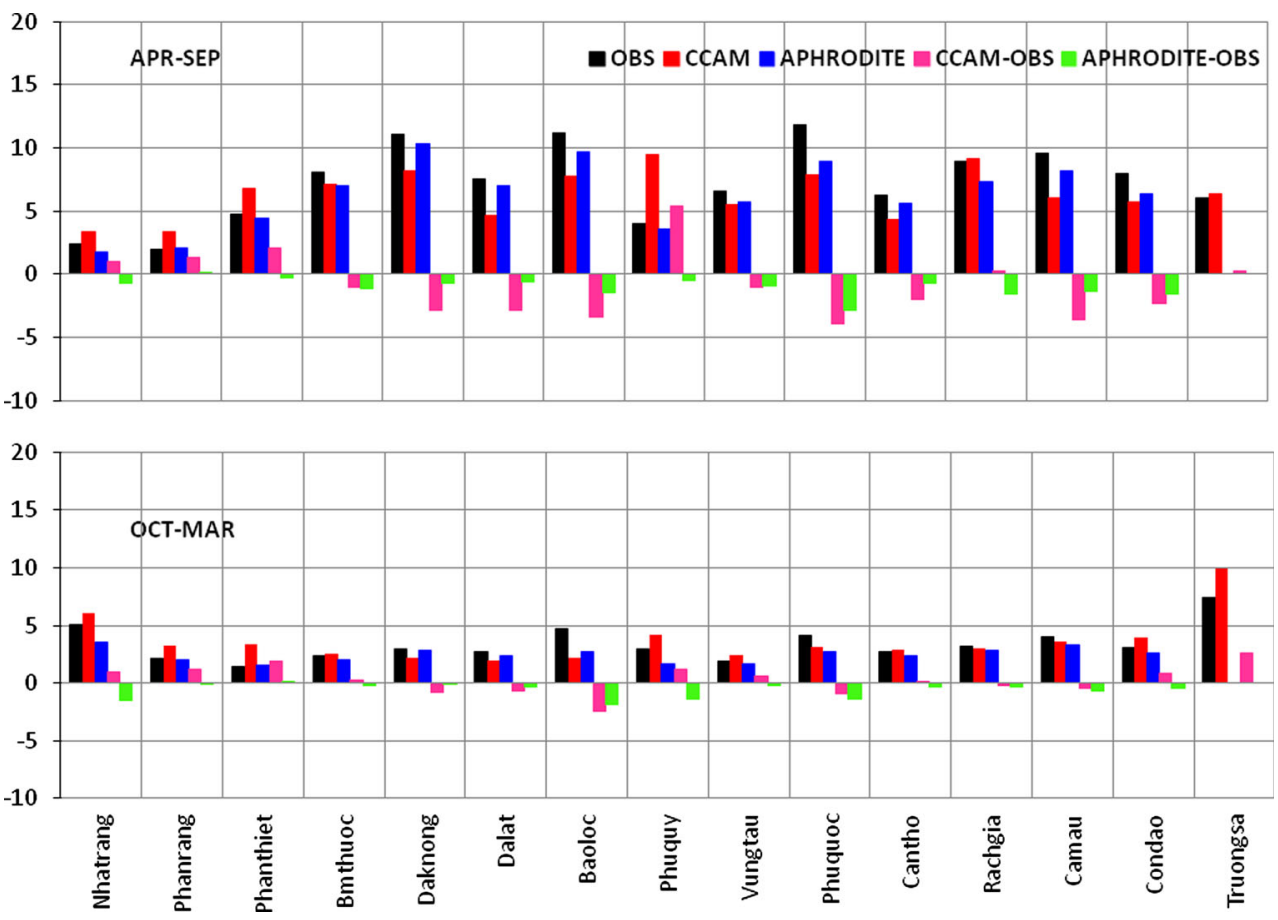

5-10 mm day ${ }^{-1}$, except Aluoi, Namdong, Tramy and Bato stations in the dry season which have observed rainfall rate above $10 \mathrm{~mm} \mathrm{day}^{-1}$. The stations are located between $14^{\circ} \mathrm{N}$ and $16^{\circ} \mathrm{N}$ and are on the eastern side of the Truong Son Range (pink squares) and at high elevation. In particular Aluoi is on the slopes of the Truong Son Range, with CCAM elevation of $790 \mathrm{~m}$. The rainfall in this region for October and November is mostly from a combination of orographic effects (see Fig. 1a), tropical cyclones and ITCZ. Both CCAM and APHRODITE provide insufficient rainfall compared to these stations, with APHRODITE a little less than CCAM, with Bato station having a bias of $10 \mathrm{~mm} \mathrm{day}{ }^{-1}$. At other sites, both CCAM and APHRODITE capture well the observed station rainfall, with biases less than $5 \mathrm{~mm}$ day $^{-1}$.

In South Vietnam (Fig. 10), there is a contrast between the wet and dry seasons. In the wet season, rainfall is 5-10 $\mathrm{mm} \mathrm{day}^{-1}$, except for Nhatrang, Phanrang and Phuquy stations, which CCAM and APHRODITE capture well. The rainfall bias is less than $5 \mathrm{~mm} \mathrm{day}^{-1}$ in the wet season, where both tend to underestimate the observed station rainfall. In the dry season, there is very little rainfall in South Vietnam and the rainfall rate is under $5 \mathrm{~mm}$ day $^{-1}$ at most stations, except Truongsa, which is located at the southeast corner in Fig. $1 \mathrm{~b}$ and is unresolved (i.e. an ocean point) in CCAM and missing in APHRODITE. Note that CCAM results in better agreement with the APHRODITE rainfall because this is a gridded data set at a comparable resolution and its rainfall magnitudes apply to an area-averaged grid box $(20 \mathrm{~km} \times 20 \mathrm{~km})$. On the other hand, station-observed rainfall is compared to values from the nearest CCAM grid point.

\subsection{Forecast skill scores for the three regions}

Forecast skill scores for rainfall are based upon www. cawcr.gov.au/projects/verification/\#Standard_verification_ methods, and are provided in the Appendix. Note that these formulae are normally applied to short-term forecasts, whereas the current study is a long-term climatic simulation. The simulation presented here is forced by the ERAInterim analyses; it is expected that the day-to-day variations should match observations reasonably well, and thus these statistics are a reasonable measure to use here. However, it is not expected to produce values as accurate as forecasts, since the model is not initialised every day. The calculations are carried out for daily rainfall measured at 12 UTC for both observed station rainfall and for CCAM-simulated rainfall evaluated at the nearest grid points. The skill score parameters used are accuracy (5), bias (6), probability of detection (POD, 7), false alarm ratio (FAR, 8), probability of false detection (POFD, 9), success ratio (SR, 10), critical success index (CSI, 11) and equitable threat score (ETS, 12).

The validation is performed for daily rainfall at a range of different thresholds: $1,5,10$ and $20 \mathrm{~mm} \mathrm{day}^{-1}$. Note that $20 \mathrm{~mm} \mathrm{day}^{-1}$ rainfall is around the 95th percentile for the regions (not shown). The results are represented in Table 2 for the three regions defined above. For the $1 \mathrm{~mm} \mathrm{day}^{-1}$ threshold, CCAM forecast accuracy is 0.71 for North Vietnam, with $71 \%$ of all forecasts correct for 
Table 2 Skill scores at different thresholds using observed station rainfall, with number in brackets representing the best scores that the model could achieve

\begin{tabular}{|c|c|c|c|c|c|c|c|c|}
\hline & Accuracy (1) & Bias (1) & POD (1) & FAR (0) & POFD (0) & SR (1) & CSI (1) & ETS (1) \\
\hline \multicolumn{9}{|c|}{$1 \mathrm{~mm} \mathrm{day}^{-1}$} \\
\hline North & 0.71 & 1.41 & 0.69 & 0.50 & 0.29 & 0.50 & 0.40 & 0.22 \\
\hline Central & 0.66 & 1.54 & 0.75 & 0.51 & 0.38 & 0.49 & 0.42 & 0.19 \\
\hline South & 0.65 & 1.49 & 0.67 & 0.53 & 0.37 & 0.47 & 0.38 & 0.16 \\
\hline \multicolumn{9}{|c|}{$5 \mathrm{~mm} \mathrm{day}^{-1}$} \\
\hline North & 0.80 & 1.09 & 0.47 & 0.55 & 0.12 & 0.45 & 0.29 & 0.20 \\
\hline Central & 0.77 & 1.32 & 0.58 & 0.55 & 0.19 & 0.45 & 0.33 & 0.22 \\
\hline South & 0.72 & 1.26 & 0.45 & 0.64 & 0.20 & 0.37 & 0.25 & 0.13 \\
\hline \multicolumn{9}{|c|}{$10 \mathrm{~mm} \mathrm{day}^{-1}$} \\
\hline North & 0.86 & 0.62 & 0.28 & 0.55 & 0.05 & 0.45 & 0.20 & 0.16 \\
\hline Central & 0.83 & 1.03 & 0.45 & 0.56 & 0.10 & 0.44 & 0.28 & 0.21 \\
\hline South & 0.80 & 0.97 & 0.29 & 0.69 & 0.10 & 0.33 & 0.17 & 0.10 \\
\hline \multicolumn{9}{|c|}{$20 \mathrm{~mm} \mathrm{day}^{-1}$} \\
\hline North & 0.92 & 0.41 & 0.17 & 0.58 & 0.02 & 0.42 & 0.13 & 0.11 \\
\hline Central & 0.90 & 0.77 & 0.33 & 0.57 & 0.04 & 0.43 & 0.22 & 0.19 \\
\hline South & 0.89 & 0.77 & 0.17 & 0.76 & 0.05 & 0.24 & 0.10 & 0.07 \\
\hline
\end{tabular}

rainfall exceeding $1 \mathrm{~mm} \mathrm{day}^{-1}$. The accuracy is slightly less for Central (0.66) and South (0.65) Vietnam. The bias is greater than 1 , around 1.5 for all three regions, which indicates that the simulation overestimates by about $50 \%$ the frequency of observed events. The fraction of events correctly forecast is between 0.67 and 0.75 which is indicated by POD. The false alarm ratio (FAR) is around 0.50 indicating that around $50 \%$ of forecast events did not occur. POFD is between 0.30 and 0.40 which indicates that about $60-70 \%$ of the observed non-events are correctly forecasted. The success ratio (SR) is between 0.45 and 0.5 , implying that less than $50 \%$ of forecast events are actually observed. The occurrence of model forecast events which correspond to the observed events is about $40 \%$ (CSI), whereas the occurrence of model forecast events accounting for random hits (ETS) is $20 \%$ or less. Note that the simulations presented here were initialised only at the start, with the digital filter applied only for systems broader than about $700 \mathrm{~km}$, every $6 \mathrm{~h}$. Therefore there is no forcing provided at small scales from the reanalysis to capture the local (station) rain events at exactly the right location or time. In addition, the CCAM rainfall is extracted from the nearest grid point to the observed station.

As the threshold value increases (which is equivalent to forecast of heavy rainfall events), the accuracy increases due to more days of correct negatives (not shown); correct negatives are equivalent to rain days with less than the threshold value. Similar to the accuracy, POFD is also improved with increasing threshold due to increase in correct negatives. The bias becomes less than one, which means that the model under-forecasts the observed high- intensity rainfall, in particular for North Vietnam. Other skill scores such as CSI and ETS are degraded with increasing thresholds due to a decrease in hit rates and increase in miss rates and false alarm rates (not shown). The ratio of hit rates to miss rates decreases faster than the ratio of hit rates to the false alarm rates as the threshold increases. This confirms that CCAM reproduces observed light rainfall better than heavy rainfall events. It also suggests that CCAM has more difficulty capturing the exact timing of the rare heavier-rainfall events.

In order to test the ability of the model to capture longerterm heavy rainfall events, 3-day and 5-day running means were applied to both the time-series of the observed station data and the nearest model grid point prior to the calculation of the skill score. Both the 10 and $20 \mathrm{~mm}$ thresholds were evaluated for the SR, CSI and ETS. While complete results are not presented here, the results from the 5-day running means show that at the $10 \mathrm{~mm}$ threshold there is 10-30\% improvement to all three skill scores for all regions, with the Central region the most improved. At the $20 \mathrm{~mm}$ threshold, there is improvement for the Central region by $20-30 \%$ for the three skill scores. However the three skill scores are degraded for the North and South Vietnam regions.

\subsection{Temporal verification of CCAM performance}

\subsubsection{Inter-annual variability}

This validation is based on the time series of the wet and dry seasonal means. There are 23 years for the wet 
Fig. 11 Temporal standard deviation $\left(\mathrm{mm} \mathrm{day}^{-1}\right)$ of the wet (top) and dry (lower) season rainfall for the period 1979-2001 with observed APHRODITE (left) and CCAM (right)
TEMPORAL STANDARD DEVLATION OF RAINFAIL

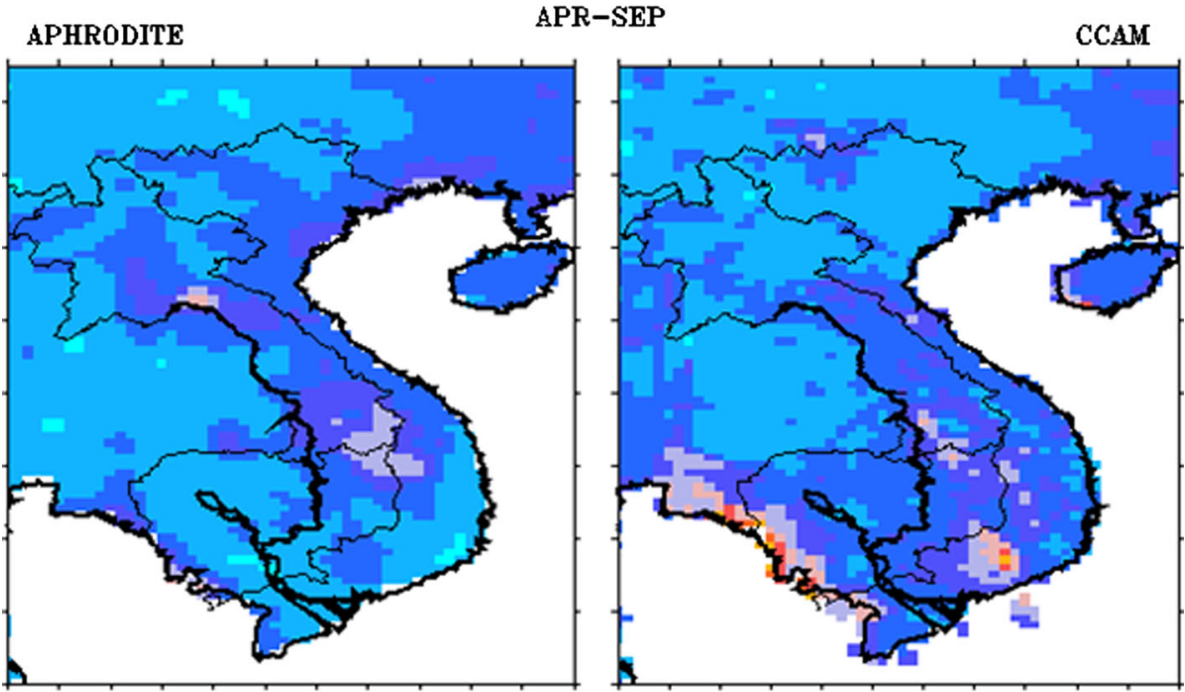

OCT-MAR

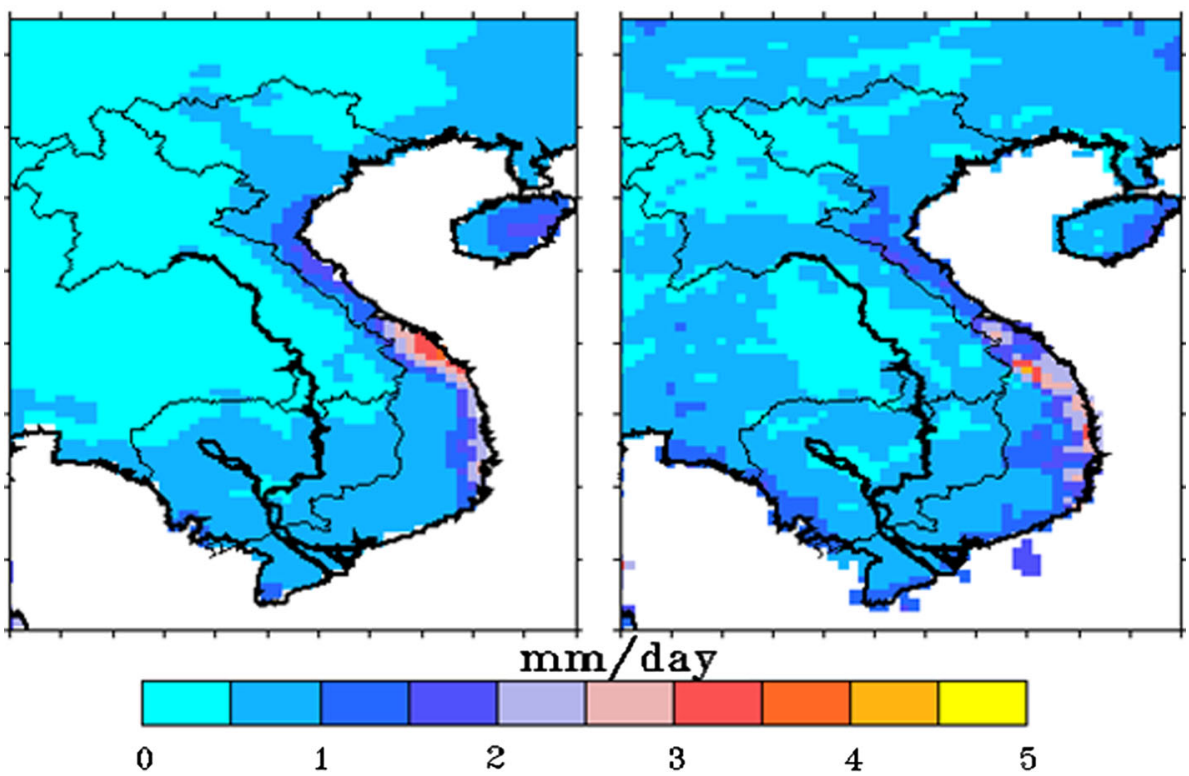

seasons (April to September); there are 22 years for the dry seasons (October-March) for the period from 1979 to 2001. CCAM should be able to reasonably capture temporal variability of the observed rainfall patterns at the seasonal and annual time scales due to the large-scale 6-hourly forcing from the ERA-Interim analyses. The temporal standard deviation of the wet and dry season mean rainfall for the period 1979-2001 was computed and is shown in Fig. 11 for APHRODITE analyses (left) and the CCAM simulation (right). In general, CCAM simulates the pattern of variability quite well. The year to year variation of rainfall in both the observations and the CCAM simulation is around $2-3 \mathrm{~mm} \mathrm{day}^{-1}$ and the largest variation is along the coast. However, CCAM overestimates this variation along the east coast of the
Gulf of Thailand and for South Vietnam compared to the observations in the wet season.

\subsubsection{Temporal correlation}

The temporal correlation of CCAM rainfall and APHRODITE rainfall for 23(22) wet (dry) seasons is shown in Fig. 12, with significance levels above $95 \%$ shaded. Over Vietnam, southeast China and Thailand, CCAM is skilful in reproducing the inter-annual rainfall variability for the dry season (right panel), with a large area having correlation coefficients above 0.6 . In the wet season (left panel) CCAM shows some skill in capturing this rainfall feature over the northern part of Central (north of $16^{\circ} \mathrm{N}$ ) to North Vietnam, southeast China and most of Laos. However, it 
Fig. 12 Temporal correlation with APHRODITE rainfall for the wet (left) and dry (right) seasons at $95 \%$ significance for the period 1979-2001
Fig. 13 Root mean square error (RMSE) of CCAM against APHRODITE daily rainfall for the wet (left) and dry (right) seasons

TEMPORAL CORRELATION OF RAINFALL
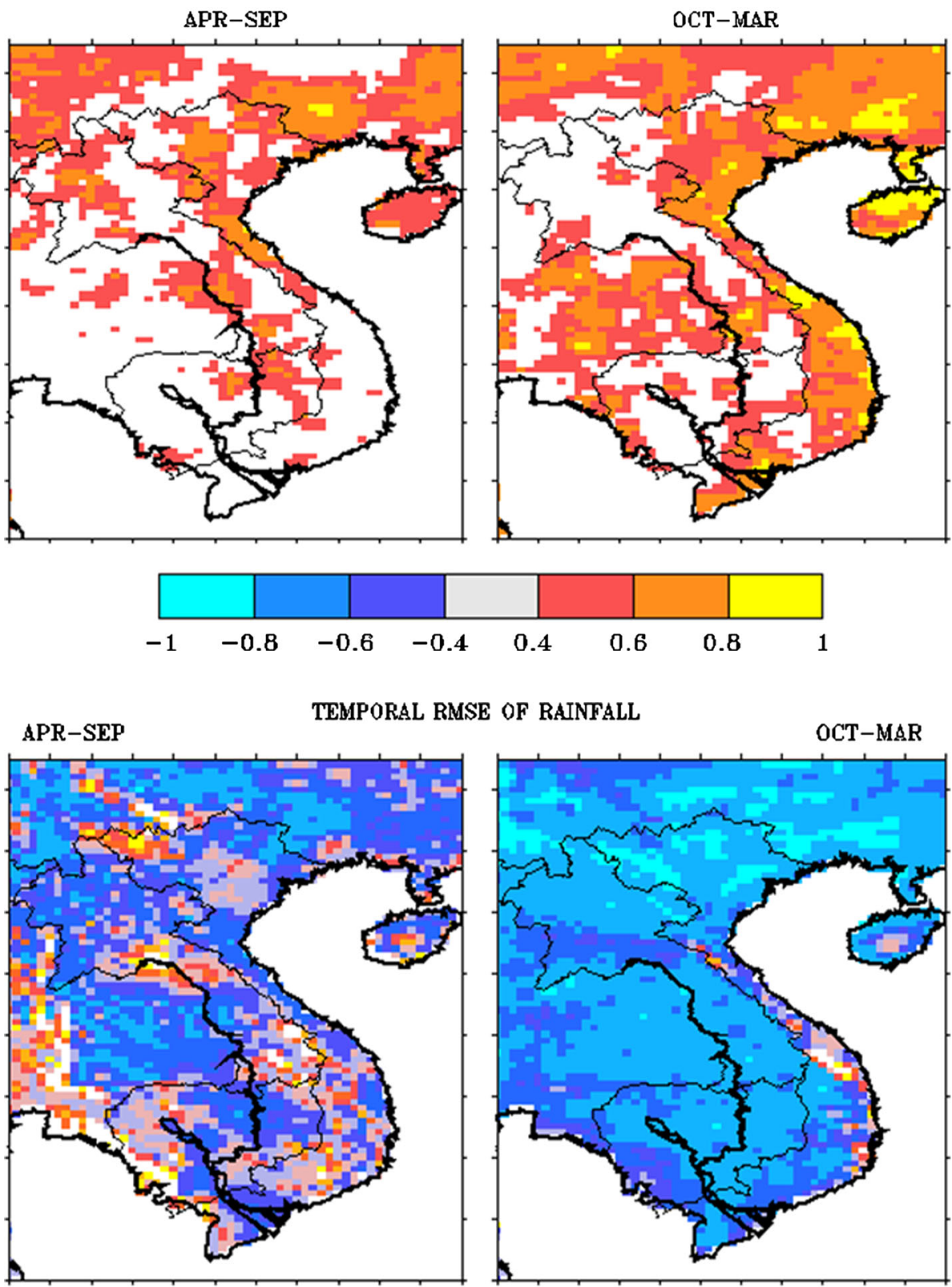

OCT-MAR
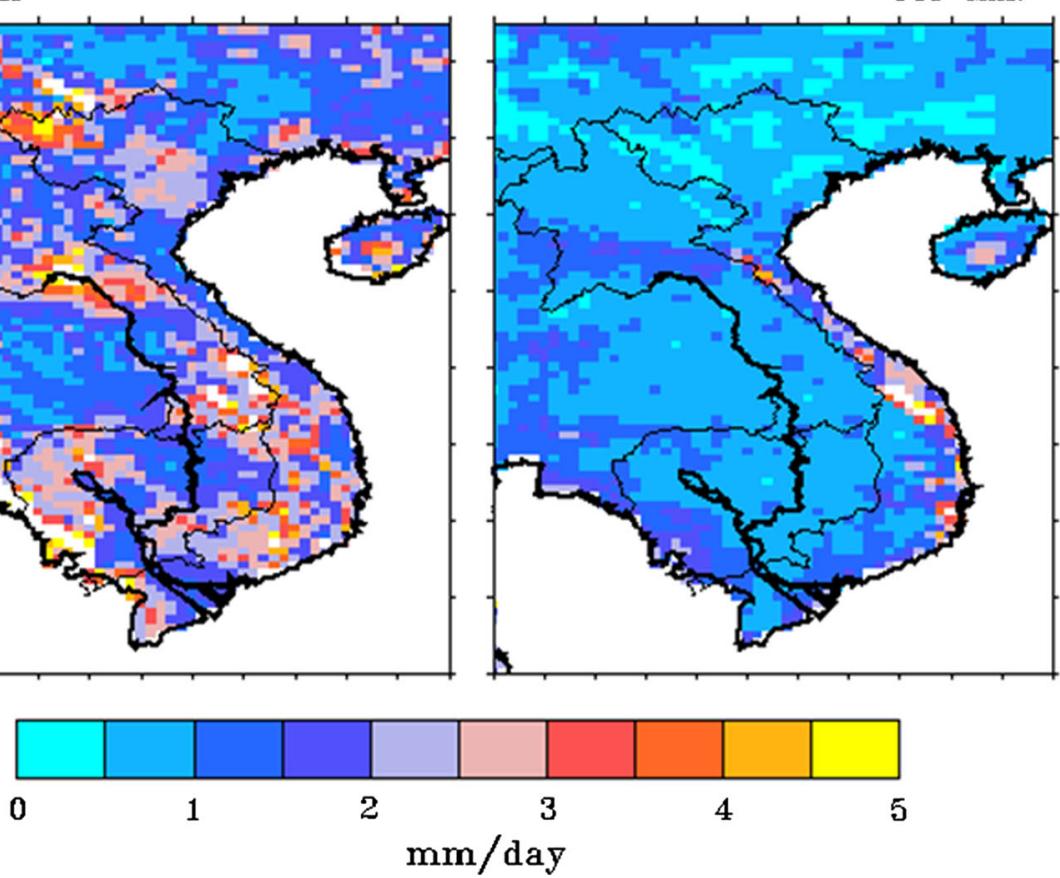

has no skill for temporal correlation over Thailand, Cambodia, and Vietnam south of $16^{\circ} \mathrm{N}$, i.e. the southern part of Central Vietnam down to South Vietnam.

\subsubsection{Root mean square error (RMSE) of temporal distribution of rainfall}

Temporal RMSE is shown in Fig. 13 for the mean rainfall of the wet/dry seasons. The RMSE value is from 1 to
$5 \mathrm{~mm}$ day $^{-1}$. In general, the patterns of RMSE are similar to those in the biases above (Fig. 6), with the largest errors in the wet season. For the dry season, the errors are along the eastern side of the Truong Son range. The mean absolute error (MAE) is also studied (not shown) where it has similar magnitude and pattern to that of RMSE.

In summary, from the analysis of Figs. 6 and 13, CCAM overestimates the APHRODITE rainfall on the windward side of the high terrain, where rainfall is strongly related to 
Fig. 14 Temporal correlation coefficients (upper) and temporal standard deviation $\left(\mathrm{mm} \mathrm{day}{ }^{-1}\right.$, lower $)$ of CCAM against observed APHRODITE based on area-averaged daily rainfall of each year for the three regions: north (black), central (red) and south (blue) over the studied period 1979-2001 for land only
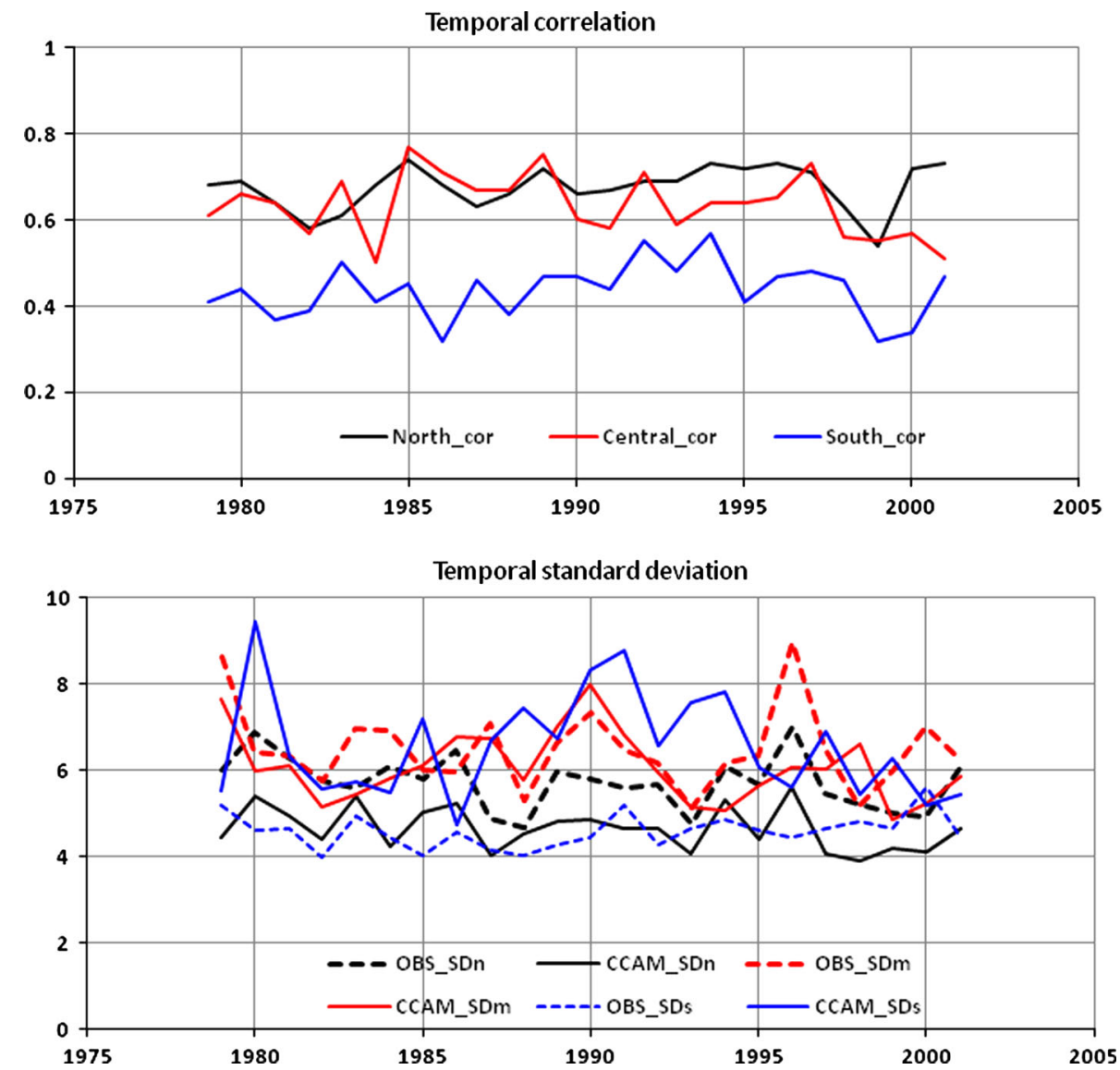

the interaction between winds and elevation. On examination, most of the simulated rainfall is found to be (perhaps excessively) large-scale in this region, and this probably leads to CCAM providing too-strong feedback to the vertical velocities upwind of orography.

\subsubsection{Temporal verification for subregions}

In Vietnam, the characteristic climate is different for the North and South regions compared to the Central region, which has more complex orography (Fig. 1a). From Figs. 8, 9, and 10 above, the wet and dry seasons are distinct for North and South Vietnam, but not for the Central region. At some locations (Hue, Aluoi, Namdong, Danang, Tramy, Quangngai and Bato) in Central Vietnam, rainfall in the dry seasons is even larger than in the wet seasons, due to tropical cyclones, ITCZ and winter monsoon. Further investigation into CCAM performance in capturing temporal variation of daily rainfall over the three subregions is made by computing the temporal standard deviation and temporal correlation. The three subregions are North Vietnam $\left(104-110^{\circ} \mathrm{E}\right.$ and $\left.19.5-25^{\circ} \mathrm{N}\right)$, Central Vietnam $\left(106-110^{\circ} \mathrm{E}\right.$ and $\left.12-19^{\circ} \mathrm{N}\right)$ and South Vietnam $\left(104-110^{\circ} \mathrm{E}\right.$ and $\left.8-11.5^{\circ} \mathrm{N}\right)$. This validation is based on each region's area-averaged daily rainfall from the
APHRODITE analysis and the CCAM simulations only over land. There are three reasons for using APHRODITE daily rainfall instead of the observed station daily rainfall. From the above study for the three regions in Vietnam, we see that APHRODITE reproduces well the observed station rainfall, except for a few stations in Central Vietnam and one station over North Vietnam. Secondly, there are days with missing data in the observed station daily rainfall. Thirdly, this Section mainly investigates the temporal variability of daily rainfall not the rainfall amount. For the remainder of this study, we only use APHRODITE rainfall. The calculation is carried out for each year, for the period 1979-2001, with the results shown in Fig. 14.

From Fig. 14, we see that CCAM performs well in North (black line) and Central (red line) Vietnam, with temporal correlation (upper panel) of 0.7-0.8 except for 1993 and 2001, where the correlation for Central Vietnam drops to 0.6 and 0.63 , respectively. CCAM also captures well the temporal standard deviation of the observed (dashed line, lower panel) rainfall over these two regions (with slight underestimation of rainfall in North Vietnam), where the daily rainfall variation is around 5-6 $\mathrm{mm}_{\text {day }}{ }^{-1}$ for North Vietnam and 6-8 $\mathrm{mm} \mathrm{day}^{-1}$ for Central Vietnam. However, in South Vietnam, CCAM performs poorly with temporal correlation coefficient between 0.5 and 0.6 ; 
Fig. 15 Log-log plot of number of days with rainfall sorted into bins with a bin width of $5 \mathrm{~mm}$ day $^{-1}$ for the three subregions: north (top left), central (top right) and south (bottom left). Solid line is the perfect-fit line, dashed line is a linear fit through the data points, with the equations and coefficient of determination $\left(R^{2}\right)$ for each line of the three subregions shown. The data point at the top right corner in each plot represents the lowest rainfall bin $0-5 \mathrm{~mm} \mathrm{day}{ }^{-1}$, the next data point represents bin 5-10 $\mathrm{mm} \mathrm{day}^{-1}$ and so on. The size of the circle corresponds to the bin range. Therefore heavy rainfall bins are located near the lower left corner, such as green (50-55 $\left.\mathrm{mm} \mathrm{day}^{-1}\right)$, olive (55-60 mm day $\left.{ }^{-1}\right)$, light blue (60-65 $\left.\mathrm{mm} \mathrm{day}^{-1}\right)$ and dark brown $\left(65 \mathrm{~mm} \mathrm{day}^{-1}\right.$ and above)
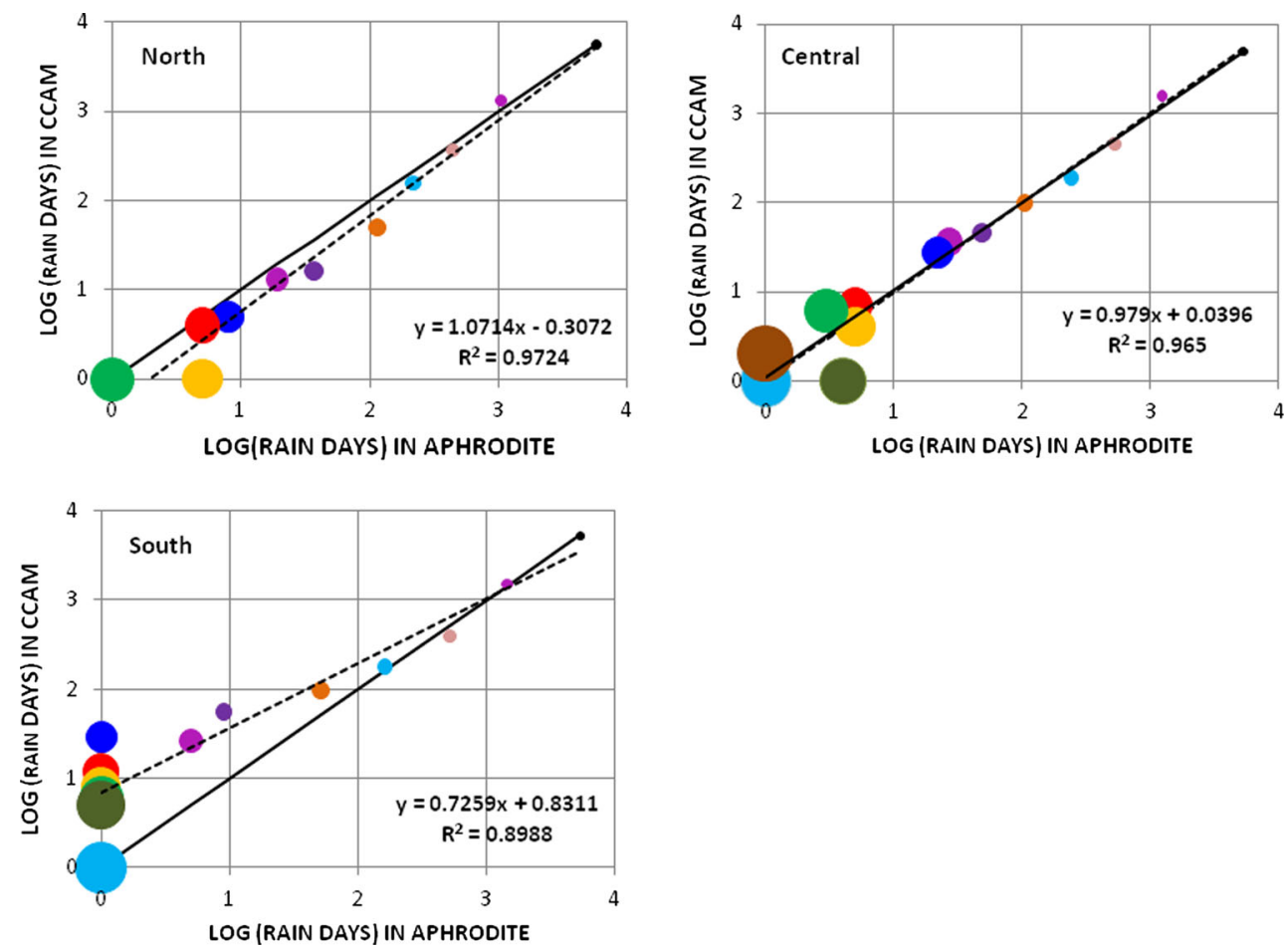

CCAM performs worst for 1980, 1986 and 1999, where the correlation coefficients are only around 0.4. This poor performance is also reflected in the temporal standard deviation (blue solid and dashed lines in the lower panel), where CCAM overestimates the day to day variation of observed rainfall by about $3 \mathrm{~mm}$ day $^{-1}$ for years from 1985 to 1995, which are mostly neutral and El Niño years; worst is nearly $5 \mathrm{~mm} \mathrm{day}^{-1}$ in 1980 , which is a neutral year (based on www.cpc.ncep.noaa.gov/products/analysis_ monitoring/ensostuff/ensoyears.shtml). This result for the subregion in South Vietnam is consistent with the findings in Figs. 6, 11 and 13 above.

Next we study the probability density function (PDF) of rain days over the three subregions described in Fig. 14. The number of rain days is sorted into $5 \mathrm{~mm} \mathrm{day}^{-1}$ bins. The distribution for rain days sorted into bins is plotted in Fig. 15 on a $\log -\log$ scale, where the horizontal axis represents the APHRODITE data and the vertical axis represents CCAM data. The solid line is the perfect fitted line, the dashed line is the line fitted through the data points. The closer the solid and the dashed line, the better the agreement between CCAM and APHRODITE. If the dashed line is below/above the solid line, then CCAM under/overestimates APHRODITE. Each plot shows the equation and the coefficient of determination $\mathrm{R}^{2}$ used to describe the dashed line; the closer $R^{2}$ is to 1 , the better the dashed line represents the data points. CCAM performs exceptionally well for Central Vietnam, where the solid line and the dashed line are indistinguishable. There is only one outlier (point on the horizontal axis) and $\mathrm{R}^{2}$ is 0.965 , very close to 1 .
CCAM also performs well for North Vietnam. It slightly underestimates APHRODITE, with the solid and dashed lines close together for bins of a lower rainfall rate. The rainfall over North Vietnam is well represented by the dashed line $\left(\mathrm{R}^{2}=0.972\right)$. CCAM does not perform as well for South Vietnam where it overestimates (the dashed line is above the solid line) APHRODITE for the high rainfall bin above $25 \mathrm{~mm}$ day $^{-1}$. Note that some data points lie on the vertical axis implying that there is no corresponding observed bin; in other words the model overestimates the observations for heavy rainfall days for South Vietnam.

Note that the rainfall over Central Vietnam is dominated by the dry season (Fig. 5). In turn its rainfall is largely due to tropical cyclones and cold surges (Chen et al. 2012; Yokoi and Matsumoto 2008). Combining these PDF results and the forecast skill results discussed in Sect. 3.4 above, it tends to suggest that CCAM has some ability to simulate the mean heavy rainfall amounts for Central and to some extend North Vietnam but not the day to day variability of heavy rainfall.

\subsubsection{El Niño-Southern Oscillation (ENSO)}

ENSO plays an important role in Vietnam climate (Yen et al. 2011; Phan 2002) owing to the eastern side of Vietnam being adjacent to the western North Pacific. Classification of warm, cold and neutral seasons is based on the Nino 3.4 index published in www.cpc.ncep.noaa.gov/products/ analysis_monitoring/ensostuff/ensoyears.shtml. For wet seasons, Nino 3.4 indices are used from April-May-June 
Table 3 Years with El Niño and La Niña for the wet and dry seasons during the period 1979-2001

\begin{tabular}{lll}
\hline & Wet season & Dry season \\
\hline El Niño & 1982,1986, & $1979 / 80,1982 / 83,1986 / 87,1987 / 88$, \\
& $1987,1991,1997$ & $1991 / 92,1994 / 95,1997 / 98$ \\
La Niña & $1984,1985,1988$, & $1983 / 84,1984 / 85,1988 / 89,1995 / 96$, \\
& $1998,1999,2000$ & $1998 / 99,1999 / 2000,2000 / 01$ \\
\hline
\end{tabular}

RAINFALL ANOMALY FOR TET SEASON

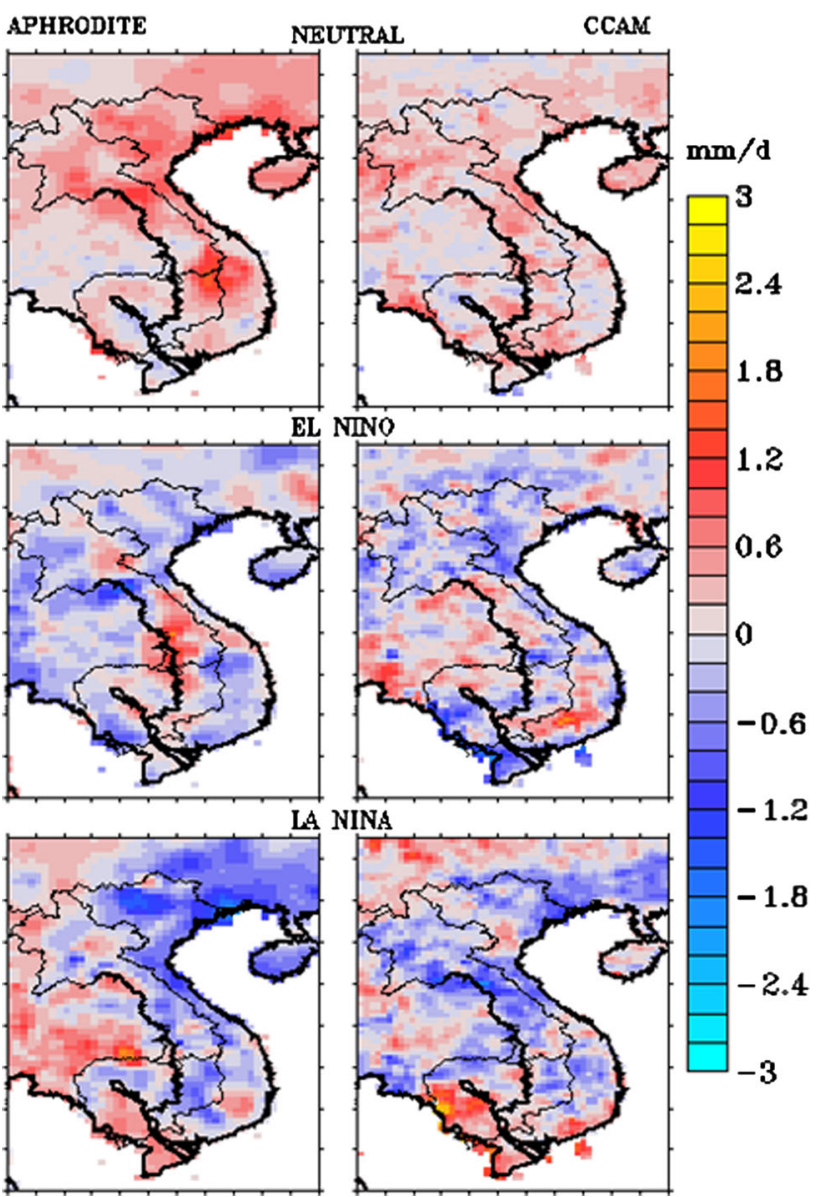

Fig. 16 Anomalous rainfall $\left(\mathrm{mm} \mathrm{day}^{-1}\right)$ for the wet season under different ENSO phases: neutral (top), El Niño (middle) and La Niña (lower), with observed APHRODITE (left) and CCAM (right). The anomaly is defined as the rainfall difference between the ENSO mean rainfall and the climatological rainfall of the corresponding season

(AMJ), May-June-July (MJJ), June-July-August (JJA) and July-August-September (JAS). For dry seasons, Nino 3.4 indices are used from October-NovemberDecember (OND), November-December-January (NDJ), December-January-February (DJF), January-FebruaryMarch (JFM). Note that January, February and March are from the following year. The season is classified as El Niño (La Niña) when $67 \%$ Nino 3.4 indices of the season are at least $0.5^{\circ} \mathrm{C}$ above (below) normal. The neutral season occurs when all Nino 3.4 indices of the season are
RAINFALL ANOMALY FOR DRY SEASON

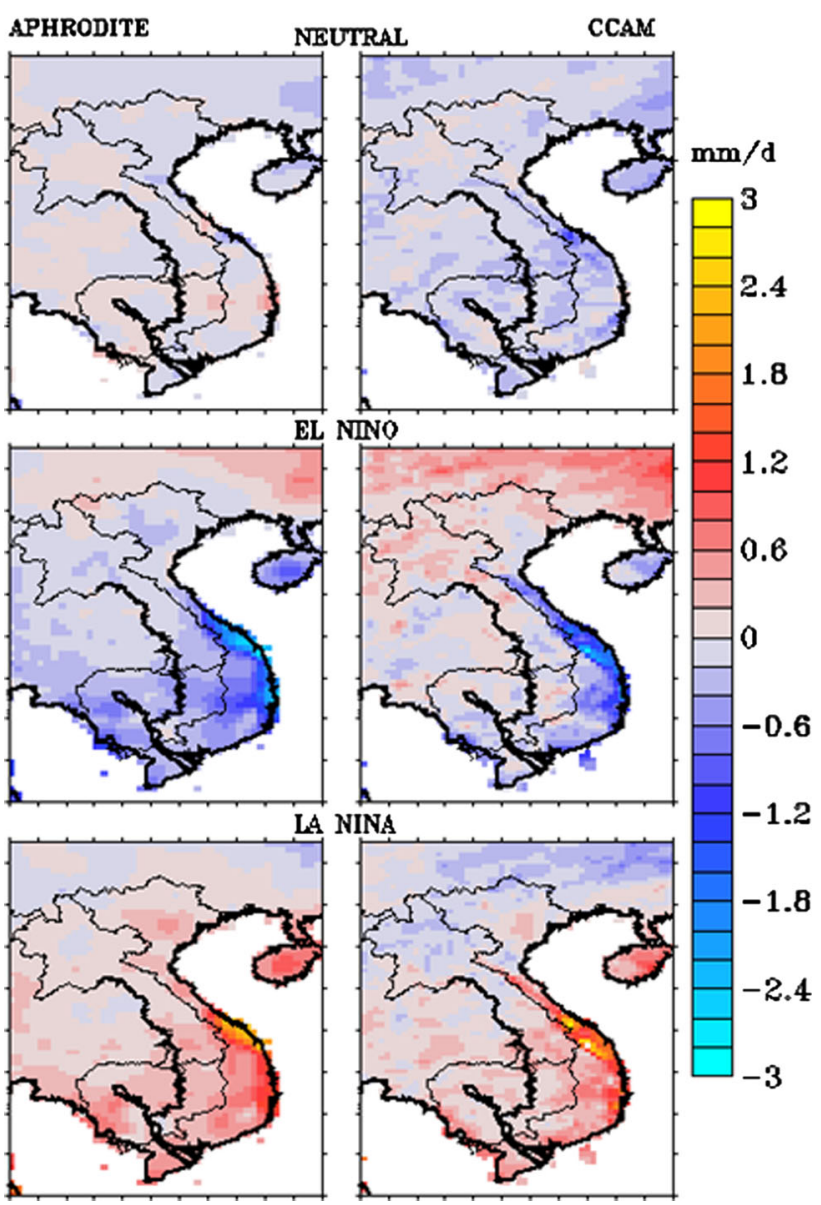

Fig. 17 As in Fig. 16 but for the dry season

between -0.5 and $+0.5{ }^{\circ} \mathrm{C}$. More details can be found in the above website. For the studied period from 1979 to 2001 (see Table 3), the wet season had six La Niñas and five El Niños, while during the dry season there were seven La Niñas and seven El Niños.

The impact of ENSO on rainfall from APHRODITE and the CCAM simulation is shown in Figs. 16 and 17 for the wet and dry seasons, respectively. The anomaly is the deviation from the climatological mean for the period 1979-2001 of the corresponding season. In the wet season (Apr-Sep, Fig. 16), the near-surface wind entering the region is from the southeast (see Fig. 2). The influence of ENSO on the rainfall is more evident over Thailand, Laos and Cambodia, with a deficiency in El Niño years (Fig. 16 middle panel) and more rainfall in La Niña years (Fig. 16 lower panel). Along the east coast of Vietnam, there is not much difference between the two ENSO phases.

In the neutral years (Fig. 16 top panels), the rainfall is enhanced over northern Vietnam, which CCAM slightly underestimates (Fig. 16 top panel and right). CCAM does not reproduce the drier (wetter) conditions over Thailand in 
El Niño (La Niña) years, which may relate to deficiencies in the simulation of the impact of ENSO on the southwesterly monsoon in this region. In south-central regions of Vietnam, CCAM and APHRODITE also disagree on the sign of the changes during El Niño years (middle panels in Fig. 16), with CCAM producing wetter conditions, whereas APHRODITE produces drier conditions. A check was carried out against seven observed stations shown in Fig. 1b for the south-central Vietnam region. For El Niño years (Table 3), average rainfall anomaly for these stations is $+0.11 \mathrm{~mm} \mathrm{day}^{-1}$, which is consistent with above-normal rainfall in CCAM (middle-right panel in Fig. 16). Also, La Niña years for the northwest region of Vietnam, CCAM (anomalies of -0.5 to $-1 \mathrm{~mm} \mathrm{day}^{-1}$ ) are less dry than in APHRODITE (anomalies of -1.2 to $-1.6 \mathrm{~mm} \mathrm{day}^{-1}$ ). However, the rainfall anomalies for the two stations in this region are -0.28 and $-0.91 \mathrm{~mm} \mathrm{day}^{-1}$, which are more similar to CCAM than APHRODITE.

In the dry season (Fig. 17), when the wind is coming from the western Pacific (Fig. 2, lower panel) the influence of ENSO is more evident along the east coast of Vietnam, where there is less rainfall in El Niño years and more rainfall in La Niña years and small changes in the neutral years compared to normal seasons. CCAM captures this behaviour quite well for all the ENSO conditions.

The rainfall pattern correlation for the ENSO phases is low in the wet season, with values of 0.26 for neutral, 0.27 for El Niño and 0.17 for La Niña years, mainly because the rainfall has small-scale variations which are poorly captured by the model. The rainfall pattern correlation is greater in the dry season, especially for El Niño and La Niña years, with values of 0.29 for neutral, 0.62 for El Niño and 0.56 for La Niña years, because rainfall in the dry season is influenced by the large-scale variations which are better simulated by the model than in the wet season. In general, CCAM tends to under- (over-) estimate rainfall from APHRODITE in neutral (El Niño) years for northern Vietnam during the wet season.

\section{Conclusions}

We completed a CCAM simulation for the current climate over Vietnam with large-scale forcing from ERA-Interim reanalysis for the period 1979-2001. A scale-selective digital filter was used to force the winds, temperature and sea-level pressure for length scales greater than about $700 \mathrm{~km}$. The first two variables were forced for levels above terrain-following pressure-sigma values of 0.9 . The mean $10 \mathrm{~m}$ wind speed was compared with that of ERAInterim. In general, CCAM $10 \mathrm{~m}$ wind speed is stronger in both wet and dry seasons. The error is largest along the east coast of Vietnam and over SCS/EVS in the wet season, and this bias is slightly less in the dry season.

The long-term CCAM mean rainfall for Vietnam for the two seasons (wet and dry) was compared with observed APHRODITE and station data sets. CCAM reasonably simulates the APHRODITE rainfall in the dry seasons but it overestimates APHRODITE rainfall in the wet seasons. Also CCAM simulates good rainfall patterns in North and Central Vietnam, but overestimates rainfall in South Vietnam. Consequently, the CCAM bias/RMSE is largest over South Vietnam and along the east coast in the wet season; the large error is also reflected in the daily rainfall PDF for South Vietnam rainfall, with a greater number of heavy rain days produced by CCAM compared to APHRODITE. An insignificant bias/RMSE is simulated by CCAM in the dry seasons, except at some elevated stations on the east coast of the Truong Son Range.

Conformal Cubic Atmospheric Model is skilful in simulating daily rainfall at station locations, for a rainfall rate threshold of $1 \mathrm{~mm}$ day $^{-1}$. However its skill is degraded for high-rainfall-rate thresholds such as 10 and $20 \mathrm{~mm} \mathrm{day}^{-1}$. The results imply that CCAM has difficulty in simulating day-to-day heavy rainfall amounts. However it has some skill in capturing the mean conditions of the heavy rainfall amounts, at least for Central Vietnam and to some extent for North Vietnam.

The inter-annual variability of rainfall patterns is better simulated by CCAM in the dry seasons; it appears to have some difficulty in capturing the ENSO rainfall patterns for the wet seasons.

This validation provides an understanding of the capabilities of CCAM in regard to simulation of rainfall over Vietnam, when the simulation is forced by large-scale features of the ERA-Interim reanalysis. It is to be expected that the skill will be less for climate-change simulations where reanalysis forcing is no longer available.

Acknowledgments The authors would like to thank Ha Noi University of Science (HUS) and the Institute of Meteorology, Hydrology and Environment (IMHEN) for providing observed station data. The authors are also indebted to the two reviewers for their critical suggestions toward improvements of the manuscript. This project was funded by the CSIRO-AusAid Alliance to produce high-resolution downscaled future-climate data sets for Vietnam.

Open Access This article is distributed under the terms of the Creative Commons Attribution License which permits any use, distribution, and reproduction in any medium, provided the original author(s) and the source are credited.

\section{Appendix}

The spatial or temporal verification statistics are defined as follows: 
Root mean square error is defined as

$R M S E=\sqrt{\frac{\sum_{i=1}^{N}\left(\bar{O}_{i}-\bar{P}_{i}\right)^{2}}{N}}$,

where $\bar{O}_{i}$ and $\bar{P}_{i}$ are observed mean and model mean.

Mean absolute error is defined as

$M A E=\mathrm{N}^{-1} \sum_{i=1}^{N}\left|o_{i}-p_{i}\right|$.

Correlation coefficient is defined as

$\rho=\frac{\sum_{i}\left(o_{i}-\bar{o}\right)\left(p_{i}-\bar{p}\right)}{\sqrt{\sum_{i}\left(o_{i}-o\right)^{2}} \sqrt{\sum_{i}\left(p_{i}-p\right)^{2}}}$,

where $i$ refers to either time or space and $\bar{o}$ and $\bar{p}$ are observed and model means.

Index of agreement is defined as:

$I O A=1-\frac{\sum_{i=1}^{N}\left(o_{i}-p_{i}\right)^{2}}{\sum_{i}^{N}\left(\left|p_{i}-\bar{o}\right|+\left|o_{i}-\bar{o}\right|\right)^{2}}$,

where $i$ may be either spatial or temporal.

For categorical forecasts (http://www.cawcr.gov.au/ projects/verification/\#Standard_verification_methods), the verification statistics used are defined as follows:

Accuracy $=\frac{\text { hits }+ \text { correct negatives }}{\text { total }}$.

The accuracy values range from 0 to 1 , with perfect score 1

Bias score

bias $=\frac{\text { hits }+ \text { false alarms }}{\text { hits }+ \text { misses }}$.

The bias score values range from 0 to infinity, with perfect score 1, where hit is defined as an event forecast to occur, and did occur. Correct negative is an event forecast not to occur and it did not occur. False alarm is an event forecast to occur, but it did not occur. Miss is an event forecast not to occur, but it did occur.

Probability of detection (POD)

$P O D=\frac{\text { hits }}{\text { hits }+ \text { misses }}$.

The POD values range from 0 to 1 , with perfect score 1 .

False alarm rate (FAR)

$F A R=\frac{\text { false alarms }}{\text { hits }+ \text { false alarms }}$.

The FAR values range from 0 to 1 , with perfect score 0 .
Probability of false detection (POFD)

$P O F D=\frac{\text { false alarms }}{\text { correct negatives }+ \text { false alarms }}$.

The POFD values range from 0 to 1 , with perfect score 0 .

Success ratio (SR)

$S R=\frac{\text { hits }}{\text { hits }+ \text { false alarms }}$.

The SR values range from 0 to 1 , with perfect score 1 . Threat score (TS) or critical success index (CSI)

$C S I=\frac{\text { hits }}{\text { hits }+ \text { misses }+ \text { false alarms }}$.

The CSI values range from 0 to 1 , with perfect score 1 . Equitable threat score (ETS)

$E T S=\frac{\text { hits }- \text { hits }_{\text {random }}}{\text { hits }+ \text { misses }+ \text { flase alarms }- \text { hits }_{\text {random }}}$,

where

hits $_{\text {random }}=\frac{(\text { hits }+ \text { misses })(\text { hits }+ \text { false alarms })}{\text { total }}$.

The ETS values range from 0 to 1 , with perfect score 1 .

\section{References}

Adler RF, Huffman GJ, Chang A, Ferraro R, Xie P, Janowiak J, Rudolf B, Schneider U, Curtis S, Bolvin D, Gruber A, Susskind J, Arkin P, Nelkin E (2003) The Version-2 Global Precipitation Climatology Project (GPCP) monthly precipitation analysis. J Hydrometeorol 4:1147-1167

Chen TC, Tsay JD, Yen MC, Matsumoto J (2012) Interannual variation of the late fall rainfall in Central Vietnam. J Clim 25:392-413

Holtslag AAM, Boville BA (1993) Local versus non-local boundary layer diffusion in a global climate model. J Clim 6:1825-1842

Kajikawa Y, Yasunari T, Yoshida S, Fujinami H (2012) Advanced Asian summer monsoon onset in recent decades. Geophys Res Lett 39:L03803. doi:10.1029/2011GL050540

Kowalczyk EA, Garratt JR, Krummel PB (1994) Implementation of a soil canopy scheme into the CSIRO GCM-regional aspects of the model response. In: CSIRO Division of Atmospheric Research Technical Paper vol 32, p 59

Krajewski WF, Ciach GJ, McCollum JR, Bacotiu C (2000) Initial validation of the Global Precipitation Climatology Project monthly rainfall over the United States. J Appl Meteorol 39:1071-1086

Lacis AA, Hansen JE (1974) A parameterization for the absorption of solar radiation in the Earth's atmosphere. J Atmos Sci 31:118-133

Landman S, Engelbrecht FA, Engelbrecht CJ, Dyson LL, Landman WA (2012) A short-range weather prediction system for South Africa based on a multi-model approach. Water SA 38:765-774

McGregor JL (1996) Semi-Lagrangian advection on conformal-cubic grids. Mon Weather Rev 124:1311-1322 
McGregor JL (2003) A new convection scheme using a simple closure. In: Current issues in the parameterization of convection, Bureau of Meteorology, Melbourne, Australia, Technical Report vol 93, pp 33-36

McGregor JL (2005a) Geostrophic adjustment for reversibly staggered grids. Mon Weather Rev 133:1119-1128

McGregor JL (2005b) C-CAM: geometric aspects and dynamical formulation [electronic publication]. CSIRO Atmospheric Research Technical Paper vol 70, p 43

McGregor JL, Dix MR (2001) The CSIRO conformal-cubic atmospheric GCM. In: Hodnett PF (ed) IUTAM symposium on advances in mathematical modelling of atmosphere and ocean dynamics. Kluwer, Dordrecht, pp 197-202

McGregor JL, Dix MR (2008) An updated description of the Conformal-Cubic Atmospheric Model. In: Hamilton K, Ohfuchi W (eds) High resolution simulation of the atmosphere and ocean. Springer, Berlin, pp 51-76

McGregor JL, Gordon HB, Watterson IG, Dix MR, Rotstayn JD (1993) The CSIRO 9-level atmospheric general circulation model. In: CSIRO Division of Atmospheric Research Technical Paper vol 26, p 89

New MG, Hulme M, Jones PD (1999) Representing twentieth century space-time climate variability. Part I: development of a 1961-90 mean monthly terrestrial climatology. J Clim 12:829-856

Nguyen KC, Katzfey JJ, McGregor JL (2011) Global $60 \mathrm{~km}$ simulation with CCAM: evaluation over the tropics. Clim Dyn. doi:10.1007/s00382-011-1197-8

Phan VT (2002) On the tropical cyclone activity in Northwest Pacific basin and Bien Dong Sea in relationship with ENSO. J Sci, Viet Nam National University, Hanoi, t.XVIII(1):51-58

Phan VT, Ngo-Duc T, Ho TMH (2009) Seasonal and interannual variations of surface climate elements over Vietnam. Clim Res 40:49-60

Rotstayn LD (1997) A physically based scheme for the treatment of stratiform clouds and precipitation in large-scale models. I: description and evaluation of the microphysical processes. Q J R Meteorol Soc 123:1227-1282

Sarker RP (1966) A dynamical model of orographic rainfall. Mon Weather Rev 94:555-572
Schwarzkopf MD, Fels SB (1991) The simplified exchange method revisited: an accurate, rapid method for computation of infrared cooling rates and fluxes. J Geophys Res 96:9075-9096

Simmons A, Uppala S, Dee D, Kobayashi S (2006) ERA-Interim: new ECMWF reanalysis products from 1989 onwards. ECMWF Newsl 110:26-35

Thatcher M, McGregor JL (2009) Using a scale-selective filter for dynamical downscaling with the conformal cubic atmospheric models. Mon Weather Rev 137:1742-1752

Wang Z, Chang C-P (2012) A numerical study of the interaction between the large-scale monsoon circulation and orographic precipitation over South and Southeast Asia. J Clim. doi:10. 1175/JCLI-D-11-00136.1

Willmott CJ (1982) Some comments on the evaluation of model performance. Bull Am Meteorol Soc 63:1309-1313

Xie P, Arkin PA (1997) Global precipitation: a 17-year monthly analysis based on gauge observations, satellite estimates, and numerical model outputs. Bull Am Meteorol Soc 78:2539-2558

Xie SP, Xu H, Saji NH, Wang Y, Liu WT (2006) Role of narrow mountains in large-scale organization of Asian monsoon convection. J Clim 19:3420-3429

Yatagai A, Xie P, Kitoh A (2005) Utilization of a new gauge-based daily precipitation dataset over monsoon Asia for validation of the daily precipitation climatology simulated by the MRI/JMA 20-km-mesh AGCM. SOLA 1:193-196. doi:10.2151/sola.2005050

Yatagai A, Kamiguchi K, Arakawa O, Hamada A, Yasutomi N, Kitoh A (2012) APHRODITE: constructing a long-term daily gridded precipitation dataset for Asia based on a dense network of rain gauges. Bull Am Meteorol Soc. doi:10.1175/BAMS-D-1100122.1

Yen M-C, Chen T-C, Hu H-L, Tzeng R-Y, Dinh DT, Nguyen TTT, Wong CJ (2011) Interannual variation of the fall rainfall in Central Vietnam. J Meteorol Soc Jpn 89A:259-270

Yokoi S, Matsumoto J (2008) Collaborative effects of cold surge and tropical-type disturbance on heavy rainfall in Central Vietnam. Mon Weather Rev 136:3275-3287 